\title{
Inter-laboratory comparison of cryogenic water extraction systems for stable isotope analysis of soil water
}

Natalie Orlowski ${ }^{1,2,12}$, Lutz Breuer ${ }^{2,3}$, Nicolas Angeli ${ }^{4}$, Pascal Boeckx $^{5}$, Christophe Brumbt ${ }^{6}$, Craig S. Cook $^{7}$, Maren Dubbert $^{8,22}$, Jens Dyckmans ${ }^{9}$, Barbora Gallagher ${ }^{10}$, Benjamin Gralher ${ }^{11}$, Barbara Herbstritt ${ }^{12}$,

Pedro Hervé-Fernández ${ }^{5,6,13}$, Christophe Hissler ${ }^{14}$, Paul Koeniger ${ }^{15}$, Arnaud Legout ${ }^{16}$, Chandelle Joan Macdonald ${ }^{7}$, Carlos Oyarzún $^{6}$, Regine Redelstein ${ }^{17}$, Christof Seidler ${ }^{18}$, Rolf Siegwolf ${ }^{19}$, Christine Stumpp ${ }^{11,20}$, Simon Thomsen $^{21}$, Markus Weiler $^{12}$, Christiane Werner ${ }^{8,22}$, and Jeffrey J. McDonnell ${ }^{1}$

${ }^{1}$ Global Institute for Water Security, School of Environment and Sustainability, University of Saskatchewan,

Saskatoon, Canada

${ }^{2}$ Institute for Landscape Ecology and Resources Management (ILR), Research Centre for BioSystems,

Land Use and Nutrition (IFZ), Justus Liebig University Giessen, Giessen, Germany

${ }^{3}$ Centre for International Development and Environmental Research, Justus Liebig University Giessen, Giessen, Germany

${ }^{4}$ INRA-UHP Ecologie et Ecophysiologie Forestières, INRA Centre de Nancy, Champenoux, France

${ }^{5}$ Isotope Bioscience Laboratory (ISOFYS), Faculty of Bioscience Engineering, Ghent University, Ghent, Belgium

${ }^{6}$ Instituto de Ciencias de la Tierra, Universidad Austral de Chile, Valdivia, Chile

${ }^{7}$ Department of Ecosystem Science and Management, Stable Isotope Facility, University of Wyoming,

Laramie, Wyoming, USA

${ }^{8}$ BayCEER, University of Bayreuth, Bayreuth, Germany

${ }^{9}$ Institute of Soil Science and Forest Nutrition, Centre for Stable Isotope Research and Analysis (KOSI),

University of Göttingen, Göttingen, Germany

${ }^{10}$ Institute for Environmental Research, Australia Nuclear Science and Technology Organization, Sydney, Australia

${ }^{11}$ Institute of Groundwater Ecology, German Research Center for Environmental Health, Helmholtz Zentrum München,

Neuherberg, Germany

${ }^{12}$ Hydrology, Faculty of Environment and Natural Resources, University of Freiburg,

Freiburg, Germany

${ }^{13}$ Laboratory of Hydrology and Water Management, Faculty of Bioscience Engineering, Ghent University, Ghent, Belgium

${ }^{14}$ Luxembourg Institute of Science and Technology (LIST), Department of Environmental Research and Innovation (ERIN),

Esch-sur-Alzette, Luxembourg, Luxembourg

${ }^{15}$ German Federal Institute for Geosciences and Natural Resources (BGR), Hanover, Germany

${ }^{16}$ INRA UR1138 Biogéochimie des Ecosystèmes Forestiers, INRA Centre de Nancy, Champenoux, France

${ }^{17}$ Plant Ecology and Ecosystems Research, University of Göttingen, Göttingen, Germany

${ }^{18}$ Ecophysiology of Plants, Technical University of Munich, Munich, Germany

${ }^{19}$ Stable Isotope Research Facility, Paul Scherrer Institute (PSI), Villigen, Switzerland

${ }^{20}$ Institute of Hydraulics and Rural Water Management (IHLW), University of Natural and Life Sciences (BOKU),

Vienna, Austria

${ }^{21}$ Institute of Soil Science, University of Hamburg, Hamburg, Germany

${ }^{22}$ Ecosystem Physiology, University of Freiburg, Freiburg, Germany

Correspondence: Natalie Orlowski (natalie.orlowski@hydrology.uni-freiburg.de)

Received: 13 March 2018 - Discussion started: 15 March 2018

Revised: 14 June 2018 - Accepted: 21 June 2018 - Published: 6 July 2018

Published by Copernicus Publications on behalf of the European Geosciences Union. 
Abstract. For more than two decades, research groups in hydrology, ecology, soil science, and biogeochemistry have performed cryogenic water extractions (CWEs) for the analysis of $\delta^{2} \mathrm{H}$ and $\delta^{18} \mathrm{O}$ of soil water. Recent studies have shown that extraction conditions (time, temperature, and vacuum) along with physicochemical soil properties may affect extracted soil water isotope composition. Here we present results from the first worldwide round robin laboratory intercomparison. We test the null hypothesis that, with identical soils, standards, extraction protocols, and isotope analyses, cryogenic extractions across all laboratories are identical. Two standard soils with different physicochemical characteristics along with deionized (DI) reference water of known isotopic composition were shipped to 16 participating laboratories. Participants oven-dried and rewetted the soils to 8 and $20 \%$ gravimetric water content (WC), using the deionized reference water. One batch of soil samples was extracted via predefined extraction conditions (time, temperature, and vacuum) identical to all laboratories; the second batch was extracted via conditions considered routine in the respective laboratory. All extracted water samples were analyzed for $\delta^{18} \mathrm{O}$ and $\delta^{2} \mathrm{H}$ by the lead laboratory (Global Institute for Water Security, GIWS, Saskatoon, Canada) using both a laser and an isotope ratio mass spectrometer (OA-ICOS and IRMS, respectively). We rejected the null hypothesis. Our results showed large differences in retrieved isotopic signatures among participating laboratories linked to soil type and soil water content with mean differences compared to the reference water ranging from +18.1 to $-108.4 \%$ o for $\delta^{2} \mathrm{H}$ and +11.8 to $-14.9 \%$ or for $\delta^{18} \mathrm{O}$ across all laboratories. In addition, differences were observed between OA-ICOS and IRMS isotope data. These were related to spectral interferences during OA-ICOS analysis that are especially problematic for the clayey loam soils used. While the types of cryogenic extraction lab construction varied from manifold systems to single chambers, no clear trends between system construction, applied extraction conditions, and extraction results were found. Rather, observed differences in the isotope data were influenced by interactions between multiple factors (soil type and properties, soil water content, system setup, extraction efficiency, extraction system leaks, and each lab's internal accuracy). Our results question the usefulness of cryogenic extraction as a standard for water extraction since results are not comparable across laboratories. This suggests that defining any sort of standard extraction procedure applicable across laboratories is challenging. Laboratories might have to establish calibration functions for their specific extraction system for each natural soil type, individually.

\section{Introduction}

The interpretation of the stable isotope signatures of water $\left(\delta^{2} \mathrm{H}\right.$ and $\left.\delta^{18} \mathrm{O}\right)$ from soils in many research disciplines relies on accurate, high-precision measurements (Wassenaar et al., 2012). To extract water from soils for isotopic analysis, cryogenic water extraction (CWE) is the most widely used laboratory-based removal technique (Araguás-Araguás et al., 1995; Orlowski et al., 2016a). The ability to obtain measurable amounts of water from small sample sizes (i.e., $<10 \mathrm{~g}$ ) makes this method attractive. However, CWE is also accompanied by high capital and operating costs. Despite its widespread use, recent work has identified several extraction artifacts leading to uncertain isotopic signature identification (Gaj et al., 2017a; Orlowski et al., 2016b). Studies have shown that extraction conditions (i.e., extraction time, temperature, and vacuum) need to be adapted specifically to the soil used (Araguás-Araguás et al., 1995; Gaj et al., 2017a; Meißner et al., 2014; Orlowski et al., 2016a). Notwithstanding, isotope effects triggered by physicochemical soil properties (e.g., clay minerals; soil organic carbon content; and water content, WC) can occur (Araguás-Araguás et al., 1995; Gaj et al., 2017a; Meißner et al., 2014; Oerter et al., 2014; Orlowski et al., 2013). However, the ecohydrology and soil science communities currently lack clear recommendations for standardized water extraction conditions from soils. Although there seems to be an agreement on the need to control the extraction yield of cryogenic extraction facilities (recovery rate in percentage of previously added water), there exists a large variability in the applied extraction conditions between laboratories. Moreover, extraction systems vary in terms of heating elements, size of extraction containers, or throughput, in addition to the aforementioned extraction conditions (Goebel and Lascano, 2012; Koeniger et al., 2011; Orlowski et al., 2013). Thus, no standard system setup or methodology exists.

Despite the work to date and the extensive application of stable water isotope analysis, no formal interlaboratory comparison between different cryogenic systems has been published. Here we present the first worldwide interlaboratory comparison between 16 different cryogenic extraction facilities. CWE procedures were conducted with two standard soils with different physicochemical characteristics (silty sand and clayey loam), spiked with a known isotopic label at different gravimetric water contents (WC of 8 and $20 \%$ ). The null hypothesis guiding this work was that all laboratories would yield the same results independent of soil type and water content. In addition, we addressed the following research questions:

1. How does the cryogenic system configuration affect resulting soil water isotopic composition?

2. How do soil type and soil water content affect the isotope data? 
Table 1. Description of the respective extraction systems that participated in the cryogenic inter-laboratory comparison, the applied extraction parameters for extraction approach I, and the amount of sample material used for both extraction methods (lab procedure: I; predefined: II). Note that not every lab provided the same detailed information.

\begin{tabular}{|c|c|c|c|c|c|}
\hline Lab no. & Country & Description of CWE facility & $\begin{array}{l}\text { Number } \\
\text { of ex- } \\
\text { traction } \\
\text { slots }\end{array}$ & $\begin{array}{l}\text { Extraction parameters for } \\
\text { approach I }\end{array}$ & $\begin{array}{l}\text { Amount of sam- } \\
\text { ple material used } \\
\text { (g) }\end{array}$ \\
\hline 1 & Germany & $\begin{array}{l}\text { Similar to lab no. } 8 \text {; pair of Valco Exetainer }{ }^{\circledR} \\
\text { vials connected with a } 1.56 \mathrm{~mm} \text { stainless steel } \\
\text { capillary as extraction-collection unit; a hot } \\
\text { plate, } \mathrm{LN}_{2} \text { cold trap }\end{array}$ & 9 & $\begin{array}{l}\text { Temperature: } 100^{\circ} \mathrm{C} \text {, vacuum: } \\
1-6 \mathrm{~Pa} \text {, time: } 60 \mathrm{~min} \text { (silty sand) } \\
\text { and } 120 \text { min (clayey loam) }\end{array}$ & $10-12$ \\
\hline 2 & Canada & $\begin{array}{l}\text { Mainly composed of different types of } \\
\text { Swagelok }{ }^{\circledR} \text { fittings (Swagelok Company, } \\
\text { Solon, OH, US), flanges, and flexible hoses } \\
\text { (Rettberg }{ }^{\circledR} \text {, Rettberg Inc., Göttingen, Ger- } \\
\text { many); vacuum applied or shut off via } \\
\text { diaphragm valves and monitored via DCP } 3000 \\
\text { and VSK } 3000 \text { (Vacuubrand Inc., Wertheim, } \\
\text { Germany), glass tubes as extraction and col- } \\
\text { lection units, LN } \mathrm{LN}_{2} \text { cold trap, water bath/sand } \\
\text { bath }\end{array}$ & 24 & $\begin{array}{l}\text { Temperature: on average } 96^{\circ} \mathrm{C} \text {, } \\
\text { vacuum: } 3.3-7.3 \mathrm{~Pa} \text {, time: } 90 \mathrm{~min} \\
\text { (silty sand) and } 240 \mathrm{~min} \text { (clayey } \\
\text { loam) }\end{array}$ & 20 \\
\hline 3 & Germany & Heating lamps; $\mathrm{LN}_{2}$ cold trap & 5 & $\begin{array}{l}\text { Temperature: } \sim 115^{\circ} \mathrm{C} \text {, vacuum: } \\
1 \mathrm{~Pa} \text {, time: } 90 \mathrm{~min}\end{array}$ & 20 \\
\hline 4 & Germany & $\begin{array}{l}\text { A septum-sealed } 70 \mathrm{~mL} \text { vial (extraction) and } \\
\text { a Valco Exetainer }{ }^{\circledR} \text { vial (collection) connected } \\
\text { with a stainless steel capillary as extraction- } \\
\text { collection unit; heating block (aluminum), } \mathrm{LN}_{2} \\
\text { cold trap }\end{array}$ & 6 & $\begin{array}{l}\text { Temperature: } 125^{\circ} \mathrm{C} \text {; vacuum: } \\
50 \mathrm{~Pa} \text {; time: } 33 \mathrm{~min} \text { (silty sand at } \\
8 \% \mathrm{WC} \text { ), } 56 \mathrm{~min} \text { (silty sand at } \\
20 \% \mathrm{WC} \text { ), } 67 \mathrm{~min} \text { (clayey loam } \\
\text { at } 8 \% \mathrm{WC} \text { ), and } 83 \text { min (clayey } \\
\text { loam at } 20 \% \mathrm{WC} \text { ) }\end{array}$ & 20 \\
\hline 5 & France & Cold trap: mixture of $\mathrm{LN}_{2}$ and $\mathrm{EtOH}$ & 4 & $\begin{array}{l}\text { Temperature: } 65^{\circ} \mathrm{C} \text {, cold trap: } \\
-50 \text { to }-70^{\circ} \mathrm{C} \text {, vacuum: } 0.1- \\
1 \mathrm{~Pa} \text { (static vacuum), time: } 60- \\
90 \mathrm{~min}\end{array}$ & 10 \\
\hline 6 & Australia & $\begin{array}{l}\text { Heating tape, glassware for extraction- } \\
\text { collection unit; } \mathrm{LN}_{2} \text { cold trap }\end{array}$ & 4 & $\begin{array}{l}\text { Temperature: } 95-100^{\circ} \mathrm{C} \text {, starting } \\
\text { with sealed vacuum of } 0.3 \mathrm{~Pa} \text {, } \\
\text { time: } 150-180 \mathrm{~min}\end{array}$ & 20 \\
\hline 7 & Chile & $\begin{array}{l}\text { Heating element: reactor HI } 839800 \text { (Hanna In- } \\
\text { struments); size of extraction container: } 22 \mathrm{~mL} \text {; } \\
\text { precision measured with VD81 Thyracont } \\
\text { model }\end{array}$ & 9 & $\begin{array}{l}\text { Temperature: } 105^{\circ} \mathrm{C} \text {, vacuum: } \\
12-23 \mathrm{~Pa} \text {, time: } 240 \mathrm{~min}\end{array}$ & 20 \\
\hline 8 & Germany & $\begin{array}{l}\text { Pair of Valco Exetainer }{ }^{\circledR} \text { vials connected with a } \\
1.56 \mathrm{~mm} \text { stainless steel capillary as extraction- } \\
\text { collection unit; an aluminum block on a hot } \\
\text { plate, } \mathrm{LN}_{2} \text { cold trap }\end{array}$ & 12 & $\begin{array}{l}\text { Temperature: } 200^{\circ} \mathrm{C}, \text { vacuum: } \\
50 \mathrm{~Pa} \text {, time: } 15 \mathrm{~min}\end{array}$ & 10 \\
\hline 9 & Germany & $\begin{array}{l}\text { Stainless steel manifold (five vials each), glass } \\
\text { tubes as extraction-collection unit: } 18 \mathrm{~mm} \mathrm{w} \text {, } \\
150 \mathrm{~mm} 1, \mathrm{LN}_{2} \text { cold trap, water bath }\end{array}$ & 20 & $\begin{array}{l}\text { Temperature: } 95^{\circ} \mathrm{C}, \text { vacuum: } \\
\text { 0.8 Pa, time: } 90 \mathrm{~min}\end{array}$ & On average 43 \\
\hline 10 & Switzerland & $\begin{array}{l}\text { Glass tubes (Vacutainer), } \mathrm{LN}_{2} \text { cold trap, water } \\
\text { bath }\end{array}$ & 20 & Temperature: $80^{\circ} \mathrm{C}$ & Not specified \\
\hline 11 & USA & $\begin{array}{l}\text { Pyrex culture tubes }(25 \mathrm{~mm} \times 150 \mathrm{~mm}) \text {, vol- } \\
\text { ume: } 75 \mathrm{~mL} \text {; heaters: electric coil (only allow } \\
\text { to heat two-thirds of the tube) }\end{array}$ & 10 & $\begin{array}{l}\text { Temperature: } 102^{\circ} \mathrm{C} \text {, vacuum: } \\
<0.1-2.7 \mathrm{~Pa} \text {, time: on average } \\
81 \mathrm{~min} \text { (silty sand) and } 134 \mathrm{~min} \\
\text { (clayey loam) }\end{array}$ & $\begin{array}{l}10 \text { for } 20 \% \mathrm{WC} \text {, } \\
20 \text { for } 8 \% \mathrm{WC}\end{array}$ \\
\hline 12 & Germany & Glass tubes, $\mathrm{LN}_{2}$ cold trap, water bath & 8 & $\begin{array}{l}\text { Temperature: } 80^{\circ} \mathrm{C}, \text { vacuum: } \\
600 \mathrm{~Pa} \text {, time: } 60 \mathrm{~min}\end{array}$ & 23 \\
\hline
\end{tabular}


Table 1. Continued.

\begin{tabular}{|c|c|c|c|c|c|}
\hline Lab no. & Country & Description of CWE facility & $\begin{array}{l}\text { Number } \\
\text { of ex- } \\
\text { traction } \\
\text { slots }\end{array}$ & $\begin{array}{l}\text { Extraction parameters for } \\
\text { approach I }\end{array}$ & $\begin{array}{l}\text { Amount of sam- } \\
\text { ple material used } \\
\text { (g) }\end{array}$ \\
\hline 13 & Germany & $\begin{array}{l}\text { Glass tubes (Schott GL 18), } \mathrm{LN}_{2} \text { cold trap, } \\
\text { sensor-regulated tube-shaped heating element }\end{array}$ & 10 & $\begin{array}{l}\text { Temperature: } 100^{\circ} \mathrm{C}, \text { vacuum: } \\
6.7-13.3 \mathrm{~Pa} \text {, time: } 15-266 \mathrm{~min}\end{array}$ & $\begin{array}{l}10 \text { for } 20 \% \mathrm{WC}, \\
20 \text { for } 8 \% \mathrm{WC}\end{array}$ \\
\hline 14 & Germany & $\begin{array}{l}\text { Glass tubes as extraction units, vacuum is gen- } \\
\text { erated by a rotary vane pump (RZ } 2.5 \text {, Vac- } \\
\text { uubrand, Wertheim) and monitored via DCP } \\
3000 \text { with VSP } 3000 \text { (Vacuubrand), } \mathrm{LN}_{2} \text { cold } \\
\text { trap, water bath }\end{array}$ & 20 & $\begin{array}{l}\text { Temperature: } 80^{\circ} \mathrm{C} \text {, vacuum: } 2- \\
46 \mathrm{~Pa} \text {, time: } 30 \mathrm{~min} \text { (silty sand) } \\
\text { and } 40 \mathrm{~min} \text { (clayey loam) }\end{array}$ & 10 \\
\hline 15 & Germany & $\begin{array}{l}\text { The septa of Labco exetainers are pierced with } \\
\text { a cannula ( } 1.2 \mathrm{~mm} \text { diameter) and connected } \\
\text { to the vacuum system, vacuum is generated } \\
\text { by a rotary vane pump (RZ } 2.5 \text {, Vacuubrand, } \\
\text { Wertheim, Germany) and monitored via DCP } \\
3000 \text { with VSP } 3000 \text { (Vacuubrand), } \mathrm{LN}_{2} \text { cold } \\
\text { trap, water bath }\end{array}$ & 20 & $\begin{array}{l}\text { Temperature: } 80^{\circ} \mathrm{C} \text {, vacuum: } \\
10-350 \mathrm{~Pa} \text {, time: } 30 \mathrm{~min} \text { (silty } \\
\text { sand) and } 40 \mathrm{~min} \text { (clayey loam) }\end{array}$ & 10 \\
\hline 16 & Germany & $\begin{array}{l}\text { Mainly composed of different types of } \\
\text { Swagelok }{ }^{\circledR} \text { fittings (Swagelok Company, } \\
\text { Solon, OH, US), flanges, and flexible hoses } \\
\text { (Rettberg }{ }^{\circledR} \text {, Rettberg Inc., Göttingen, Ger- } \\
\text { many); vacuum applied or shut off via } \\
\text { diaphragm valves and monitored via DCP } 3000 \\
\text { and VSK } 3000 \text { (Vacuubrand Inc., Wertheim, } \\
\text { Germany), glass tubes as extraction and collec- } \\
\text { tion units, } \mathrm{LN}_{2} \text { cold trap, water bath/sand bath, } \\
\text { high-purity nitrogen purging system }\end{array}$ & 18 & $\begin{array}{l}\text { Temperature: } 100^{\circ} \mathrm{C} \text {, vacuum: } \\
3.1-0.9 \mathrm{~Pa} \text {, time: } 45 \mathrm{~min} \text { (silty } \\
\text { sand) and } 240 \mathrm{~min} \text { (clayey loam) }\end{array}$ & 20 \\
\hline
\end{tabular}

3. How do results differ when extracted soil water stable isotopic compositions are measured via off-axis integrated cavity output spectroscopy (OA-ICOS) vs. isotope ratio mass spectrometry (IRMS)?

4. What do we learn from this exercise for standardization of cryogenic extraction facilities?

\section{Methods}

\subsection{Experimental design}

Table 1 provides a description of the respective extraction systems that participated in the intercomparison. In total, 16 independent laboratories from seven countries took part in the trial.

Before the commencement of the round robin test, participants were asked to fill out a questionnaire (see Appendix A) to characterize their cryogenic extraction system in terms of number of extraction slots or amount of sample material usually introduced into the system (size of extraction unit). Two standard soils with different physicochemical properties (clayey loam and silty sand) from the German State Research
Institute for Agriculture (LUFA Speyer, 2015) (Table 2) were used for the interlaboratory comparison.

We chose a silty sand from which we expected water extractions to be relatively easy for each laboratory without cation ion exchange problems and a clayey loam soil, which is known to be challenging for CWE extraction systems. Clayey soils can be difficult due to interactions with the clay fraction and different types of clay minerals - the socalled adsorbed cation effect (Oerter et al., 2014). Clay soils also present challenges with regard to the tightness of water bound to mineral surfaces, which causes an additional isotope effect (Ingraham and Shadel, 1992; Oerter et al., 2014; Walker et al., 1994).

Soil samples were sieved to a grain size $<2 \mathrm{~mm}$. Soils were pre-dried at $105^{\circ} \mathrm{C}$ for $48 \mathrm{~h}$, homogenized, and shipped in tightly sealed glass bottles to the 16 independent laboratories along with deionized (DI) reference water of known isotopic composition, measured on both an IWA-45EP analyzer (OA-ICOS, Los Gatos Research Inc., Mountain View, US) $\left(\delta^{2} \mathrm{H}:-59.8 \pm 0.2 \%\right.$ and $\delta^{18} \mathrm{O}:-8.5 \pm 0.1 \%$ o $\left.n=6\right)$ and via a Delta $\mathrm{V}^{\mathrm{TM}}$ Advantage mass spectrometer (Thermo Fisher Scientific, Waltham, MA, US $)\left(\delta^{2} \mathrm{H}:-60.5 \pm 0.2 \%\right.$ and $\delta^{18} \mathrm{O}:-8.7 \pm 0.1 \%$ o, $n=6$ ). All bottles containing either soils or DI water were filled, capped tightly, and wrapped 
Table 2. Soil characteristics of clayey loam and silty sand (means \pm SD). The clay mineral composition of soil samples was determined via X-ray powder diffraction (XRD, Philips X'Pert PW 1830 equipped with a PW2273/20 tube and a theta/theta-goniometer) following Poppe et al. (2016). Values were not corrected for reference intensity ratios (RIR). Alternating strata can occur for illite, smectite, or vermiculite. X-ray fluorescence (XRF) characterization of the chemical composition (in $\% w / w$ ) was performed using an Axios spectrometer (PANalytical, EA Almelo, the Netherlands). Loss of ignition was 12.8 for the clayey loam and 1.3 for the silty sand.

\begin{tabular}{|c|c|c|}
\hline Parameter & Clayey loam & Silty sand \\
\hline $\mathrm{pH}$ value & $7.2 \pm 0.2$ & $5.0 \pm 0.3$ \\
\hline Water holding capacity $\left({\left.\mathrm{g} 100 \mathrm{~g}^{-1}\right)}\right.$ & $43.4 \pm 0.8$ & $32.1 \pm 1.4$ \\
\hline Organic carbon $(\%)$ & $2.0 \pm 0.2$ & $0.7 \pm 0.1$ \\
\hline Cation exchange capacity $\left(\mathrm{cmol}(+) \mathrm{kg}^{-1}\right)$ & $30.6 \pm 5.1$ & $4.1 \pm 0.6$ \\
\hline \multicolumn{3}{|l|}{ Particle size $(\mathrm{mm})$ distribution according to German DIN (\%) } \\
\hline$<0.002$ (clay) & 26 & 2.6 \\
\hline $0.002-0.063$ (silt) & 46.4 & 12.7 \\
\hline $0.063-2$ (sand) & 27.6 & 84.7 \\
\hline \multicolumn{3}{|l|}{ XRD analysis (relative \%) } \\
\hline Kaolinite & 18.8 & 18.8 \\
\hline Illite & 18 & 27.7 \\
\hline Chlorite & 1.2 & 19.8 \\
\hline Vermiculite & 43.4 & 2.9 \\
\hline Smectite & 0.5 & 19.8 \\
\hline Mixed layered clays/alternating strata (illite, smectite, or vermiculite) & 18.1 & 11.1 \\
\hline \multicolumn{3}{|l|}{$\mathrm{XRF}$ analysis $(\%)$} \\
\hline $\mathrm{SiO}_{2}$ & 65.1 & 92.3 \\
\hline $\mathrm{TiO}_{2}$ & 0.4 & 0.1 \\
\hline $\mathrm{Al}_{2} \mathrm{O}_{3}$ & 8.8 & 3.3 \\
\hline $\mathrm{Fe}_{2} \mathrm{O}_{3}$ & 3.1 & 0.5 \\
\hline $\mathrm{MnO}$ & 0.1 & 0.0 \\
\hline $\mathrm{MgO}$ & 1.5 & 0.1 \\
\hline $\mathrm{CaO}$ & 5.3 & 0.2 \\
\hline $\mathrm{Na}_{2} \mathrm{O}$ & 0.9 & 0.3 \\
\hline $\mathrm{K}_{2} \mathrm{O}$ & 1.7 & 1.7 \\
\hline $\mathrm{P}_{2} \mathrm{O}_{5}$ & 0.2 & 0.1 \\
\hline $\mathrm{SO}_{3}$ & 0.1 & $<0.01$ \\
\hline $\mathrm{Cl}$ & $<0.002$ & $<0.002$ \\
\hline $\mathrm{F}$ & $<0.05$ & $<0.05$ \\
\hline
\end{tabular}

with Parafilm ${ }^{\circledR}$ to prevent water loss. We decided not to ship ready-to-use rehydrated soils to avoid evaporation fractionation effects and to give participants the opportunity to adjust, for example, samples sizes to the specific requirements of their extraction system. Water loss and evaporative enrichment from the shipped DI water was checked by isotopic comparison of shipped and non-shipped DI water (shipment test 1: Giessen to Freiburg (Germany) to Saskatoon (Canada) vs. non-shipped DI water samples; shipment test 2: Giessen (Germany) to Saskatoon (Canada) vs. non-shipped DI water samples). After this simple experiment, isotope fractionation effects due to shipment were excluded.

As a reliability test, each participant in the intercomparison performed water cryogenic extractions (defined here as simply extracting pure water, i.e., without any soil material present) using their extraction facility. This was done in order to determine the capability of the respective extraction apparatus to recapture water of known isotopic composition. After showing the operational reliability, CWEs with the rehydrated soil samples were performed following a predefined protocol.

\subsection{Sample preparation protocol}

Before starting the rewetting of the pre-dried soil samples with the DI water, participants oven-dried (at $105^{\circ} \mathrm{C}$ for $48 \mathrm{~h}$ ) the provided soils again to remove any potential water that could be present (e.g., remoistening of the soil samples during shipment). Afterwards, soils were placed in a desiccator for cooling and to prevent remoistening of the dried soil samples with ambient water vapor (Orlowski et al., 2016b; Van 
De Velde and Bowen, 2013). For rehydration, two different amounts of reference DI water were added to the respective soil types (to create 8 and $20 \%$ gravimetric WC). Exposure of the dried soil samples to ambient conditions was kept as brief as possible. Participants adjusted the amount of respective soil material and water for rewetting the samples according to the specific requirements of their extraction system, e.g., size of extraction containers. Sample preparation was performed separately for OA-ICOS and IRMS analysis but in the identical way as specified below.

1. Soil and DI water were added alternately. A quarter of soil material (clayey loam or silty sand) and a quarter of DI water were alternatively added to the pre-weighed extraction tube to facilitate soil-water homogenization.

2. This rewetting procedure was completed by adding a quarter of soil material to the extraction tube to avoid supernatant water and to obtain the best possible mixing.

3. Samples were weighed again.

4. Finally, an inert cover (Fackelmann Inc, Hersbruck, Germany) was placed on top of the soil sample to avoid the spread of sample material throughout the respective cryogenic extraction line. The inert material was proven to not cause isotope effects during soil water extraction (Orlowski et al., 2013).

5. Extraction tubes were plugged and sealed with Parafilm ${ }^{\circledR}$ to ensure an airtight system.

6. Rehydrated soils in their respective extraction containers were placed in vertical position in a refrigerator $\left(5^{\circ} \mathrm{C}\right.$ for $\left.72 \mathrm{~h}\right)$, which further allowed the liquid and solid phase to equilibrate.

\subsection{Cryogenic extraction approaches}

Since different extraction times and temperatures were applied in past studies, we decided that participating laboratories should follow two different extraction approaches. (I) For the first subset of rehydrated soil samples, participants applied the CWE procedure considered routine in their laboratory for the specific soil type and soil water content. (II) With the second subset, CWE under predefined conditions for all labs was performed: for silty sand, a $45 \mathrm{~min}$ extraction time was used while $240 \mathrm{~min}$ was applied to clayey loam samples, both at an extraction temperature of $100^{\circ} \mathrm{C}$ and a vacuum of $0.3 \mathrm{~Pa}$. These predefined extraction parameters were identical for all participating laboratories. For comparison, in past studies extraction times from $2.5 \mathrm{~min}$ (Koeniger et al., 2011), over $30 \mathrm{~min}$ (West et al., 2006) to $7 \mathrm{~h}$ (Araguás-Araguás et al., 1995) for sandy soils and from $30 \mathrm{~min}$ (Goebel and Lascano, 2012), over $40 \mathrm{~min}$ (West et al., 2006) to $8 \mathrm{~h}$ (Araguás-Araguás et al., 1995) for clayey soils were reported.
Three replicates per soil type and soil water content resulting in 24 samples per extraction procedure (predefined and laboratory specific) and isotope analysis method (OAICOS and IRMS) were processed ( $n=48$ in total). Pre- and post-oven-dried $\left(105^{\circ} \mathrm{C}\right.$ for $\left.24 \mathrm{~h}\right)$ soil sample weights were used to determine water recovery rates. All extracted water samples were transferred to $2 \mathrm{~mL}$ amber glass vials capped with solid lids (Th. Geyer Inc., Renningen, Germany), tightly sealed with Parafilm ${ }^{\circledR}$, labeled, and shipped to the GIWS for isotope analysis. If the amount of extracted water was not sufficient to entirely fill the $2 \mathrm{~mL}$ vial, inserts $(0.2 \mathrm{~mL})$ were used (Th. Geyer Inc., Renningen, Germany) to minimize sample vial headspace, following standard procedures as outlined by the IAEA (2014).

\subsection{Isotope analyses}

For cross-checking isotope data and ruling out potential lab analytical differences, the isotopic composition of the extracted water samples was analyzed via both OA-ICOS and IRMS. OA-ICOS samples were analyzed on an IWA-45EP analyzer (Los Gatos Research Inc., Mountain View, US). The accuracy of OA-ICOS analyses was $\pm 0.5 \%$ for $\delta^{2} \mathrm{H}$ and $\pm 0.1 \%$ for $\delta^{18} \mathrm{O}$. IRMS samples were analyzed on a Delta $\mathrm{V}^{\mathrm{TM}}$ Advantage mass spectrometer (Thermo Fisher Scientific, Waltham, MA, US) and an H/Device peripheral using a Cr-reduction method for $\delta^{2} \mathrm{H}$ analysis (Morrison et al., 2001). For $\delta^{18} \mathrm{O}$ analysis, a GasBench II peripheral was utilized. Using mass spectrometry, a conversion from the water into a light gas suitable for mass spectrometry $\left(\mathrm{H}_{2}, \mathrm{CO}_{2}\right.$, $\mathrm{CO}, \mathrm{O}_{2}$ ) is necessary. This conversion step often turns out to limit the achievable precision of IRMS (Brand et al., 2009). In our case, IRMS results are accurate to $\pm 1 \%$ o for $\delta^{2} \mathrm{H}$ and to $\pm 0.2 \%$ or $\delta^{18} \mathrm{O}$, respectively. All isotope ratios are reported in per mil (\%o) relative to Vienna Standard Mean Ocean Water (VSMOW) $\left(\delta^{2} \mathrm{H}\right.$ or $\delta^{18} \mathrm{O}=\left(R_{\text {sample }} / R_{\text {standard }}-\right.$ 1) $\times 1000 \%$ o), where $R$ is the isotope ratio of the sample and the known reference (i.e., VSMOW) (Craig, 1961). In-house standards, calibrated against VSMOW2 and SLAP2, were run as samples to allow the results to be reported against VSMOW (Nelson, 2000).

OA-ICOS isotope data of soil water extracts were checked but not corrected for spectral interferences (caused by potentially co-extracted organics such as methanol or ethanol) using the Spectral Contamination Identifier post-processing software (LWIA-SCI, Los Gatos Research Inc.) when measured via OA-ICOS. This software compares recorded spectra from unknown samples with those from known noncontaminated samples (standards) to produce a metric of contamination from either narrowband (e.g., methanol, $\mathrm{MeOH}$ ) or broadband (e.g., ethanol, EtOH) absorbers, which indicates the likelihood or degree of spectral interference (Schultz et al., 2011). IRMS results are generally not affected by organic contaminants. 

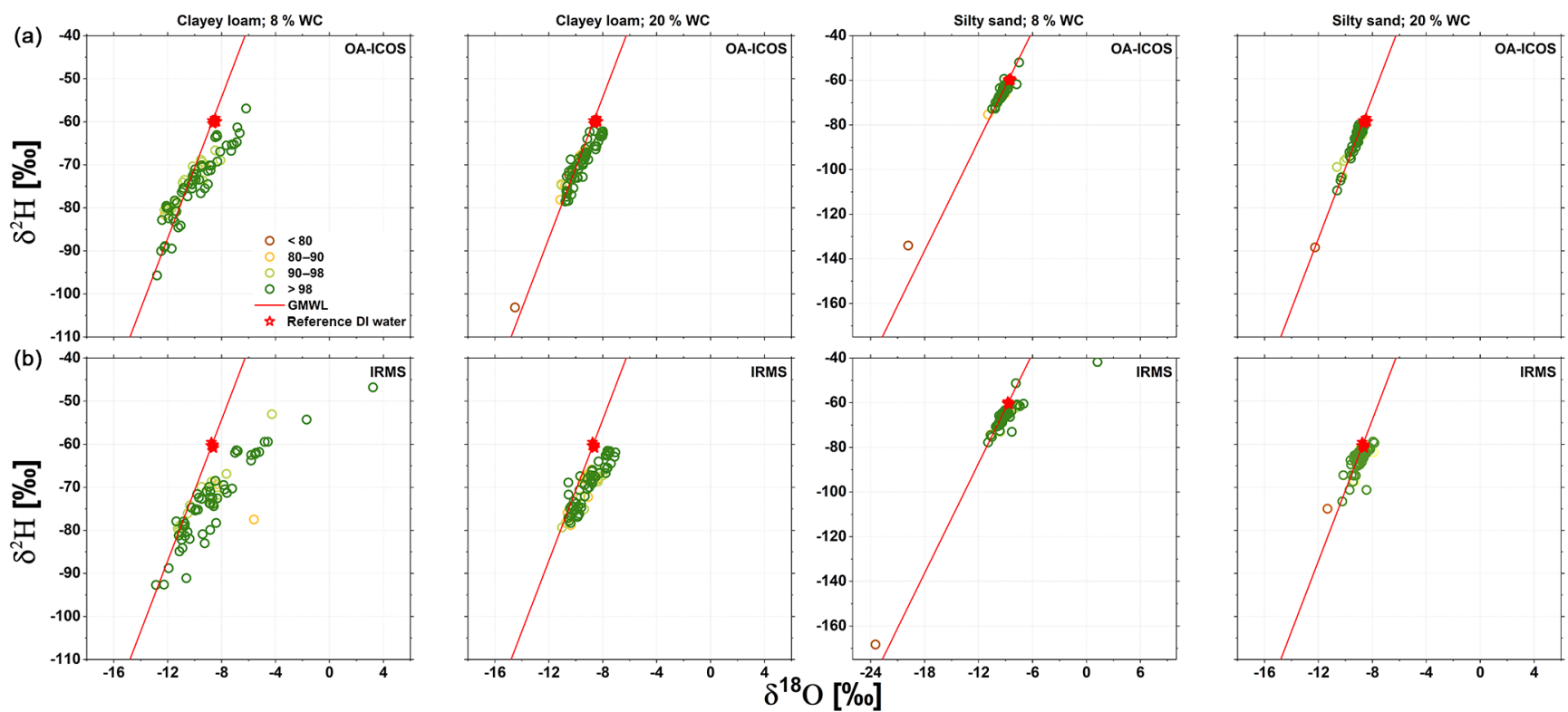

Figure 1. Water recovery rates (grouped from $<80$ to $>98 \%$ ) for both soil types (clayey loam and silty sand), WCs (8 and $20 \%$ ), and OA-ICOS and IRMS (panels a, b, respectively) isotope data in comparison to the spiked reference DI water (red asterisks) shown in dual isotope space. For reference, plots include the global meteoric water line (GMWL, solid red line). Water recovery rates are shown for those labs that provided the complete set of soil weight data (in \% of previously added water).

\subsection{Statistical evaluation}

We used $\mathrm{R}$ for statistical analyses ( $\mathrm{R}$ version 3.3.2; $\mathrm{R}$ Core Team, 2014). All data were tested for normality using the Shapiro-Wilk test for quantifying laboratory variances, differences between predefined and laboratory-specific extraction procedures, effects of soil type and $\mathrm{WC}$, and differences between OA-ICOS and IRMS. Homoscedasticity was tested using either the Levene's test for normally distributed data or the Fligner-Killeen test for non-normally distributed data. Cook's distance was determined in order to identify outliers $(D>1)$. Depending on the type of data (normally distributed and homoscedastic), either Kruskal-Wallis rank sum tests or analyses of variance (ANOVAs) were applied and post hoc tests (e.g., Nemenyi tests) were run to determine which groups were significantly different $(p \leq 0.05)$. $P$-value adjustments via the FDR method (false discovery rate) were applied to reduce the family-wise error rate (Zieffler et al., 2012).

For graphical comparisons, a target standard deviation (TSD) for acceptable performance was set to $\pm 2 \%$ for $\delta^{2} \mathrm{H}$ and $\pm 0.2 \%$ o for $\delta^{18} \mathrm{O}$, similar to Orlowski et al. (2016b), which is considered reasonable for hydrologic studies (Wassenaar et al., 2012). The TSD does not account for errors associated with the extraction method itself, weighing errors, and volumetric water additions to the sample, or any standard deviations (1 SDs) related to the isotope analysis. Statistically significant $(p \leq 0.05)$ linear regressions were added to dual isotope plots as references as well as the global meteoric water line (GMWL: $\delta^{2} \mathrm{H}=8.2 \times \delta^{18} \mathrm{O}+11.3 \%$ o, as defined by Rozanski et al., 1993).

\section{Results}

\subsection{Cryogenic extraction systems and water extraction efficiencies}

Cryogenic extraction systems varied greatly from lab to lab: from manifold, high-throughput devices (as described by Orlowski et al., 2013) to small, single chamber systems (as in Koeniger et al., 2011, and West et al., 2006) (for details see Table 1). The systems showed differences in terms of the extraction containers (form, size, volume, and material), the heating module and its application temperature (heating tapes or lamps, water baths or hot plates), the type of fittings and connections (glass, stainless steel), and in the vacuumproducing units (Table 1). In relation to the amount of used sample material, most labs either introduced 10 or $20 \mathrm{~g}$ to their system no matter the extraction approach (I or II), soil type, or WC. Only labs 11 and 13 chose different weights with respect to the WC, e.g., $10 \mathrm{~g}$ for the higher WC $(20 \%)$ and $20 \mathrm{~g}$ for $8 \% \mathrm{WC}$ for extraction approach I.

To determine the degree of extraction efficiency for each lab's samples, water recovery rates were calculated for those labs that provided the complete set of soil weight data (in \% of previously added water). When comparing water recovery rates against $\delta^{2} \mathrm{H}$ and $\delta^{18} \mathrm{O}$ values, the clayey soil showed no clear trend (Fig. 1). Even if water recovery rates were higher 

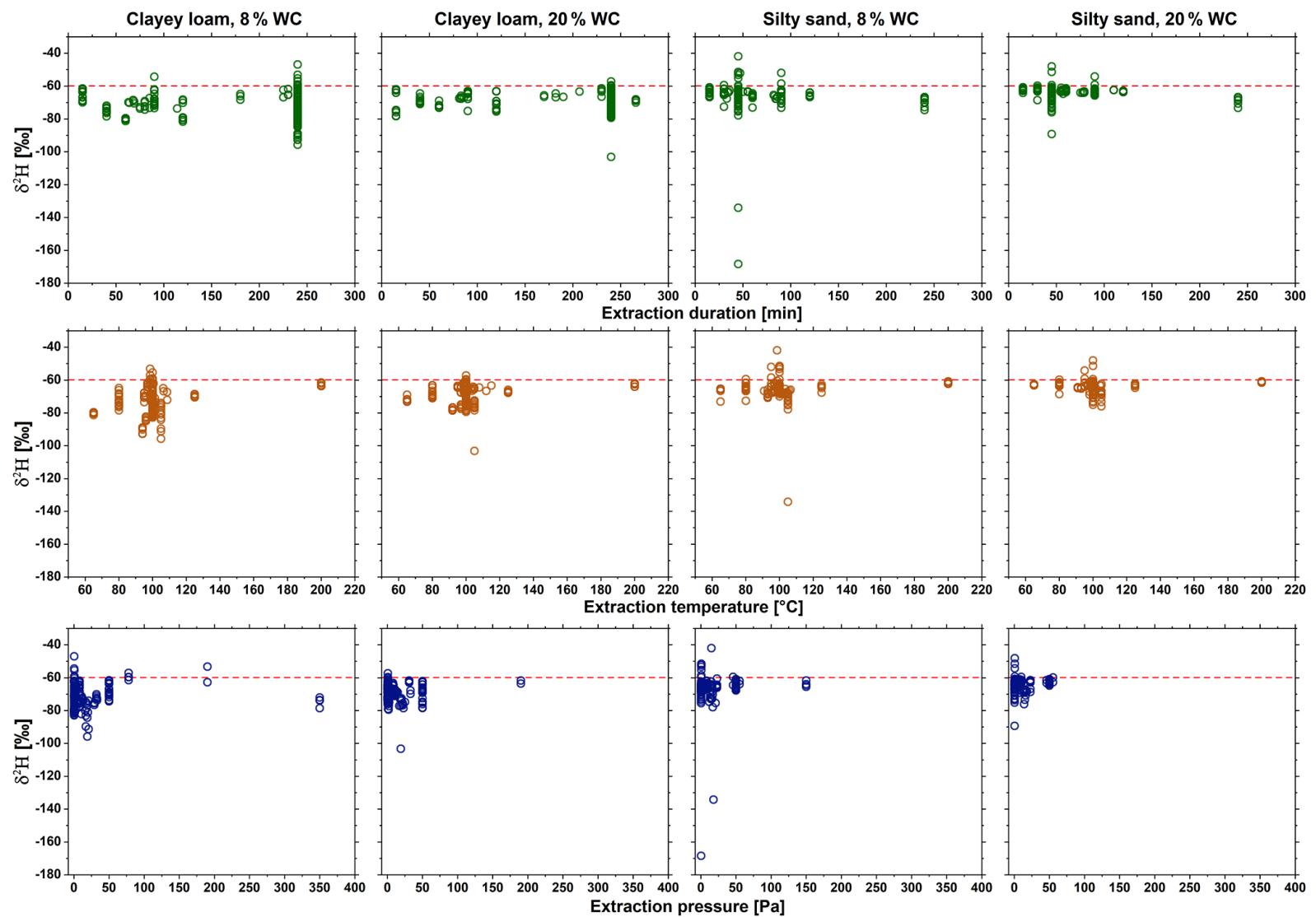

Figure 2. Effect of cryogenic extraction parameters (duration, temperature, and pressure) on $\delta^{2} \mathrm{H}$ results of both soil types (clayey loam and silty sand) and WCs (8 and $20 \%$ ) shown for all labs. The mean reference DI water $\delta^{2} \mathrm{H}$ value is shown as a red dotted line.

than $98 \%$ (following the definition of Araguás-Araguás et al., 1995), extracted isotope values differed from the reference DI water (Fig. 1). For example, at $8 \%$ soil water content (WC), recovery rates of above $98 \%$ were achieved, but isotope values were depleted in comparison to the reference DI water (Fig. 1, left panels).

For the silty sand, recovery rates were generally higher in comparison to the clayey soil. Only a few samples showed extraction efficiencies lower than $98 \%$ (Fig. 1, right panels). Surprisingly, we observed some recovery rates higher than $100 \%$. This was especially an issue for soils at $8 \% \mathrm{WC}$ (Fig. 1).

Correlation analysis was performed in order to relate extraction parameters (i.e., time, temperature, or vacuum) to OA-ICOS and IRMS isotope data.

We found no significant correlations between the extraction parameters and the respective isotope data, e.g., shown for $\delta^{2} \mathrm{H}$ results (Fig. 2) (e.g., $R^{2}=0.0$ for $\delta^{2} \mathrm{H}$ vs. duration or temperature).

\subsection{Laboratory performance with respect to water content and soil type}

Figures 3 and 4 show the mean differences between the extracted samples via the lab procedure's extraction approach I and the predefined extraction approach II compared to the reference DI water $\delta^{2} \mathrm{H}$ and $\delta^{18} \mathrm{O}$ values, respectively.

For the $8 \% \mathrm{WC}$ tests, mean differences for the clayey loam ranged from +13.1 to $-32.8 \%$ or $\delta^{2} \mathrm{H}$. For the individual lab procedure's extraction approach I at $8 \% \mathrm{WC}$ for the clayey loam, two laboratories (lab 3 and 8 ) were able to get back to the reference $\delta^{2} \mathrm{H}$ value based on no statistically significant differences $(p>0.05)$ (Fig. 3, upper left plot). For the predefined extraction approach II at $8 \% \mathrm{WC}$, two other labs recovered the $\delta^{2} \mathrm{H}$ value from the clayey loam (lab 9 and 15).

For soil samples with $20 \% \mathrm{WC}$, variation among laboratories was smaller but only one laboratory (lab 9 ) recovered the reference DI water $\delta^{2} \mathrm{H}$ value applying the predefined extraction approach for the clayey loam. Mean differences between the clayey loam extracts and the reference DI water ranged from +2.8 to $-19.5 \%$ (Fig. 3, upper right plot). 

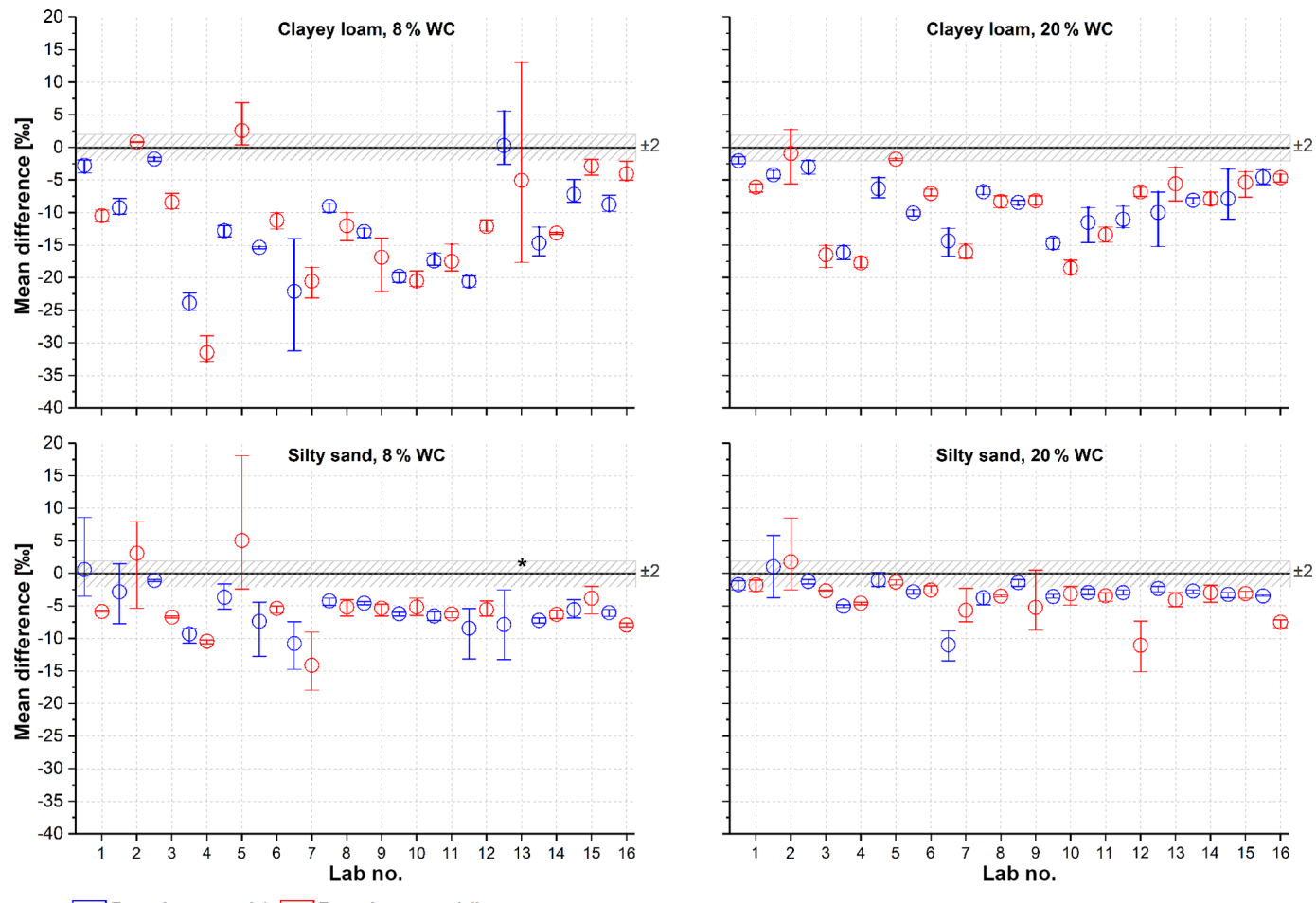

Figure 3. Mean differences from reference DI water for $\delta^{2} \mathrm{H}$ OA-ICOS results of water extracts from both extraction methods (lab procedure: I; predefined: II), soil types, and water contents ( 8 and $20 \%$ WC) including TSD of \pm 2 for $\delta^{2} \mathrm{H}$ (Asterisk: -108.4 for $\delta^{2} \mathrm{H}$ ). Symbols represent the mean of the three replicates and $y$ error bars stand for the isotopic variation of the replicates. There were no significant differences between the two extraction approaches over all labs.

Mean differences between the silty sand water extraction and the reference $\delta^{2} \mathrm{H}$ signature were in a smaller range of $\pm 18 \%$ o than clayey loam extracts from the same treatment (8\% WC).

For the individual lab procedure's extraction approach I at $8 \% \mathrm{WC}$, five laboratories recovered the added label from the silty sand (Fig. 3, lower left plot) with no statistical differences between the reference DI water $(p>0.05)$ (labs 6, $8,9,13$, and 15), whereas for the predefined extraction approach II at $8 \% \mathrm{WC}$, three labs got back to the added $\delta^{2} \mathrm{H}$ value (labs 9,12 , and 15 ).

For silty sand at $20 \%$ WC, most laboratories' results even fell close to the range of the TSD of $\pm 2 \%$. Mean differences compared to the reference DI water $\delta^{2} \mathrm{H}$ signature ranged from +8.5 to $-15.1 \%$ o (Fig. 3, lower right plot). However, extraction approach I was statistically not successful in recovering the added label $(p<0.05)$, but five laboratories (6, $9,10,14$, and 15) showed no significant differences compared to the reference DI water when applying extraction approach II to the silty sand at $20 \% \mathrm{WC}$.

Laboratories performed better for $\delta^{18} \mathrm{O}$ signature recovery, especially with extraction approach I. For both clayey loam WC treatments, labs 13 and 15 were the most successful. Again, mean differences compared to the reference DI water were larger for the $8 \% \mathrm{WC}$ than for the $20 \% \mathrm{WC}$ (Fig. 4, up- per plots). However, for the clayey loam at $20 \% \mathrm{WC}$ with the predefined approach II only lab 13 and 14 did not show statistically significant differences compared to the added $\delta^{18} \mathrm{O}$ signature (Fig. 4, upper right plot) $(p>0.05)$.

For the silty sand, most laboratories were able to get back the known value with no statistically significant differences compared to the reference $\delta^{18} \mathrm{O}$ value (Fig. 4, lower plots). For both WC treatments of the silty sand, extraction approach II seemed to work better in recovering the added label.

Across both soil types, WC treatments, and extraction approaches, lab 13 was the most successful in recovering the reference $\delta^{18} \mathrm{O}$ value, whereas for $\delta^{2} \mathrm{H}$ recovery lab 9 gained back the added label in most of the cases.

In general, $\delta^{2} \mathrm{H}$ and $\delta^{18} \mathrm{O}$ values were neither comparable between laboratories nor between one laboratory at different soil types or WCs, meaning that a specific laboratory, for example, successfully recovered the added DI water value for silty sand but was not able to gain back the known label for clayey loam. Moreover, recovery results differed between both isotopes. For example, lab 13 was the most successful for $\delta^{18} \mathrm{O}$ but not for $\delta^{2} \mathrm{H}$ signature recovery. In terms of lab internal reproducibility, some labs showed small standard deviations for the replicates of the same soil type at a given WC (Figs. 3 and 4); even so, resulting isotope values differed in a 

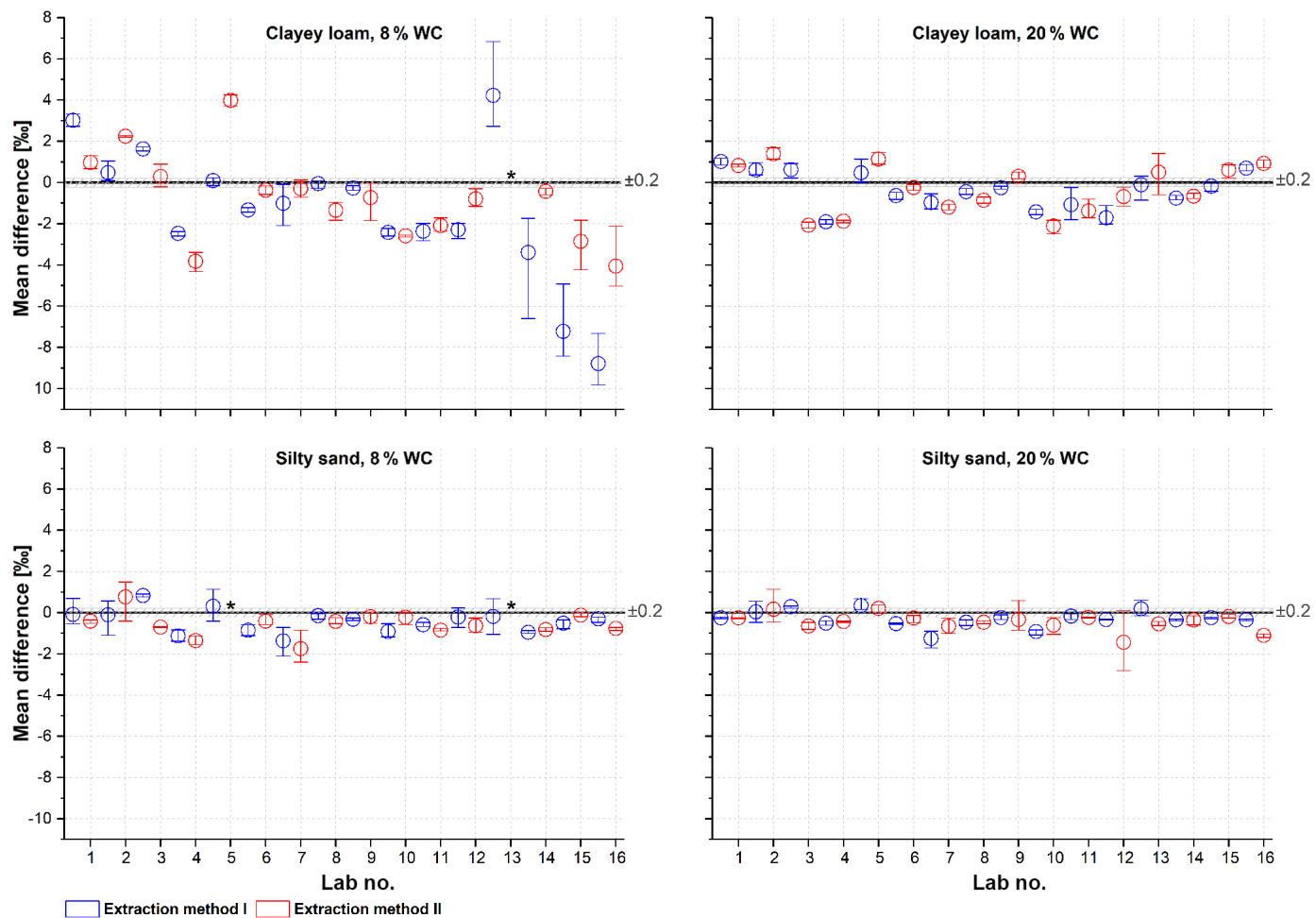

Figure 4. Mean differences from reference DI water for $\delta^{18} \mathrm{O}$ OA-ICOS results of water extracts from both extraction methods (lab procedure: I; predefined: II), soil types, and water contents ( 8 and $20 \% \mathrm{WC}$ ) including TSD of \pm 0.2 for $\delta^{18} \mathrm{O}$. Asterisks represent outliers. Symbols represent the mean of the three replicates and $y$ error bars stand for the isotopic variation of the replicates. There were no significant differences between the two extraction approaches over all labs.

statistically significant manner from the introduced reference DI water.

\subsection{Differences between OA-ICOS- and IRMS-based measurements}

Figures 5 (clayey loam) and 6 (silty sand) illustrate data variability for each laboratory and WC with respect to the labeled reference DI water added to each soil type in dual isotope space. Significant differences were observed between OAICOS and IRMS isotope data sets $(p \leq 0.05)$. The clay soil isotope data at $8 \% \mathrm{WC}$ showed the greatest differences between OA-ICOS and IRMS measurements (mean differences of 1.3 and 1.2 for $\delta^{2} \mathrm{H}$ and $\delta^{18} \mathrm{O}$, respectively). The smallest differences between isotope analyzers were observed between both WC treatments of the silty sand (Fig. 6). The data sets with the lowest SD for both isotopes across labs and extraction approaches were the silty sand samples at $20 \% \mathrm{WC}$ measured via OA-ICOS and IRMS (SD of \pm 3.1 for $\delta^{2} \mathrm{H}$ measured via OA-ICOS and \pm 4.2 for IRMS, respectively). However, those data sets still did not reach the TSD of $\pm 2 \%$ for $\delta^{2} \mathrm{H}$ and $\pm 0.2 \%$ for $\delta^{18} \mathrm{O}$.

For comparison, apart from soil water regression lines, the GMWL is also given in each subplot. Interestingly, isotope data across laboratories plot on slopes lower than the
GMWL. For both soil types, regression lines of the IRMS measurements showed better correlations (for the silty sand $R^{2}=0.8$ and 0.9 for 8 and $20 \% \mathrm{WC}$, respectively) than those of OA-ICOS measurements $\left(R^{2}=0.7\right.$ for 8 and $\left.20 \% \mathrm{WC}\right)$ (Fig. 6). Silty sand's soil water regression lines showed greater slopes (5.4-7.2 across both WCs and isotope analysis) than clayey loam's soil water regression lines (2.8-5.2 across both WCs and isotope analysis) (Figs. 5 and 6). The clayey loam regression lines for the higher WC also showed greater slopes than those of the lower WC (Fig. 5). Isotopic fractionation due to evaporation leads to a stronger kinetic effect for ${ }^{18} \mathrm{O}$ compared to ${ }^{2} \mathrm{H}$, resulting in evaporative enrichment of the water along an evaporation water line with a lower slope relative to the original water (Gonfiantini, 1986). Benettin et al. (2018) recently revised the widely used concept of evaporation lines. The authors question that the trend line passing through fractionated soil water samples correctly identifies their source water and emphasize that trend lines through evaporated samples can differ widely from true evaporation lines.

For the clay soil type, the IRMS data sets ( 8 and $20 \%$ WC) plot closer to the GMWL and the analyzed values showed a smaller SD in comparison to the OA-ICOS assays (SD of \pm 8.4 for the OA-ICOS $\delta^{2} \mathrm{H}$ data vs. \pm 7.5 for the OA-ICOS data at $8 \% \mathrm{WC}$ ) (Fig. 6). 

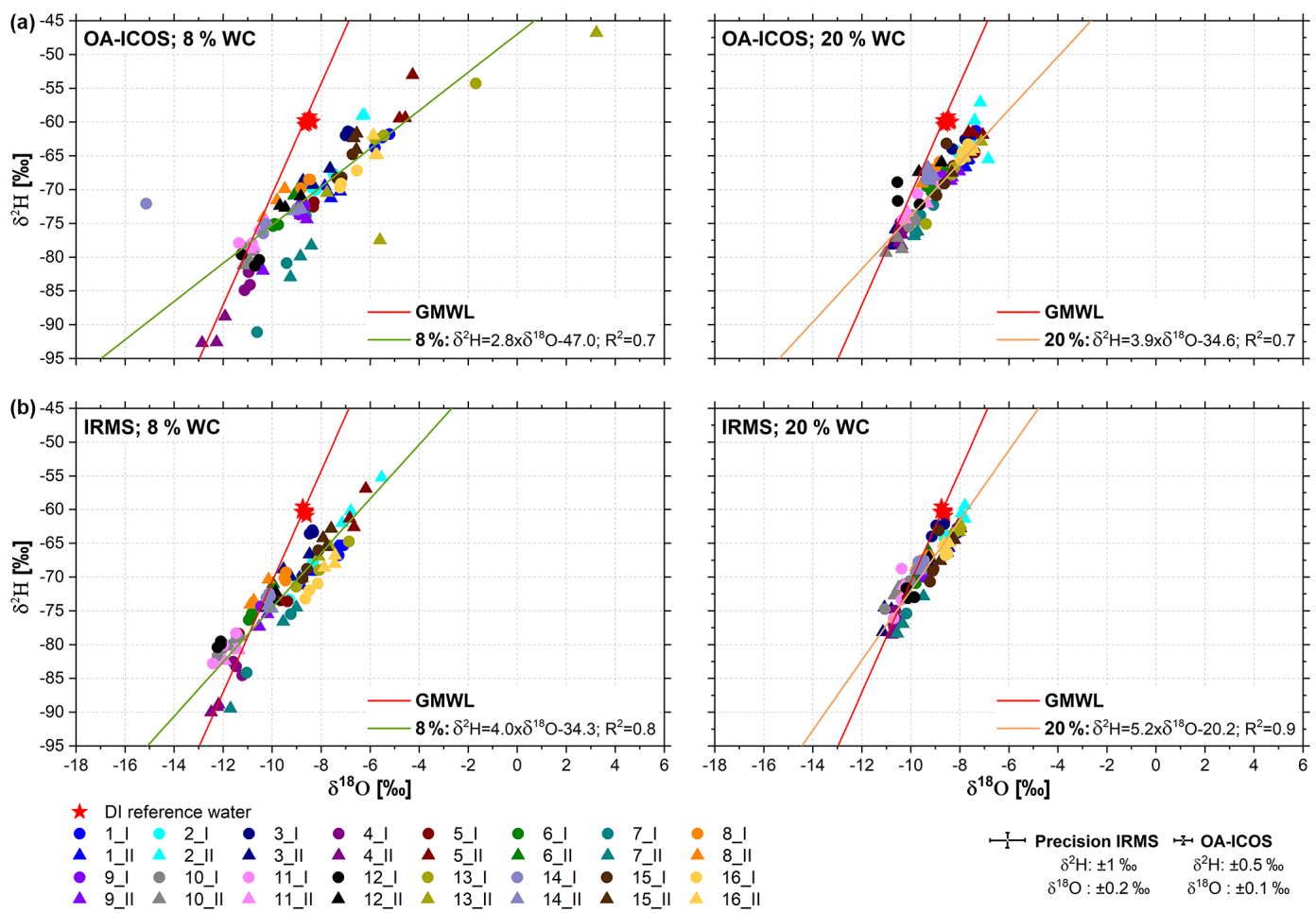

Figure 5. Dual isotope plots of clayey loam extracts for 8 and $20 \%$ WC in comparison to reference DI water (red asterisks) for OA-ICOS and IRMS data (panels a, b, respectively) from the 16 participating labs (different colors represent different labs) and both extraction methods (lab procedure: I; predefined: II). For reference, plots include the global meteoric water line (GMWL, solid red line) and soil water regression lines for 8 and $20 \% \mathrm{WC}$ (solid green and orange lines, respectively).

In general, the spread of the isotope data decreased from 8 to $20 \% \mathrm{WC}$ and from OA-ICOS to IRMS measurement results (Figs. 5 and 6). The OA-ICOS isotope analyses showed more outliers than those of IRMS. Moreover, fewer outliers were found among the silty sand data when compared to that of the clayey loam soil. Overall, IRMS results for all soil types and WCs were slightly more depleted than those of OA-ICOS. However, differences were not significant $(p>0.05)$. In general, most of the water extracts were depleted in comparison to the reference DI water, which is especially true for $\delta^{2} \mathrm{H}$.

Examination of the differences between OA-ICOS and IRMS data prompted the testing of the OA-ICOS data for spectral interferences. Figure 7 shows that for the clayey loam soil, differences between OA-ICOS and IRMS data might be due to co-extracted alcoholic compounds, which caused erroneous OA-ICOS data.

Few samples among the $8 \% \mathrm{WC}$ versions of clay water extracts showed issues with both broadband and narrowband absorbers. This contamination by both methanol and ethanol explained the outliers found at $8 \% \mathrm{WC}$ in the clayey loam data (Fig. 7, upper left plot). Among these data, only a small number of samples showed no contamination, which were interestingly more depleted in comparison to data flagged as affected by narrowband absorbers. For the silty sand soil, only a few samples were contaminated and flagged as affected by narrowband absorbers. Interestingly, outliers in the silty sand soil data set at $8 \%$ WC could not be explained by narrow- or broadband absorbers.

\section{Discussion}

\subsection{Why are the cryogenic extraction results different across the participating laboratories?}

We rejected our null hypothesis that all laboratories would yield the same results independent of soil type and water content. We showed that cryogenic extraction results were not comparable among laboratories. We also observed differences in the ability of individual labs to recover both isotope values $\left(\delta^{2} \mathrm{H}\right.$ and $\left.\delta^{18} \mathrm{O}\right)$ of the added reference DI water. Some laboratories were able to get back to the reference $\delta^{2} \mathrm{H}$ value but were not successful for $\delta^{18} \mathrm{O}$.

Each extraction system's setups were different. Therefore, it was difficult to give any recommendation with regard to a high-performance and accurate extraction system that would lead to overall successful extractions. As a quality control, we checked water recovery rates, which were in some cases even higher than $100 \%$ (Fig. 1). This could be attributed either to leaky vacuum systems (which might allow atmo- 

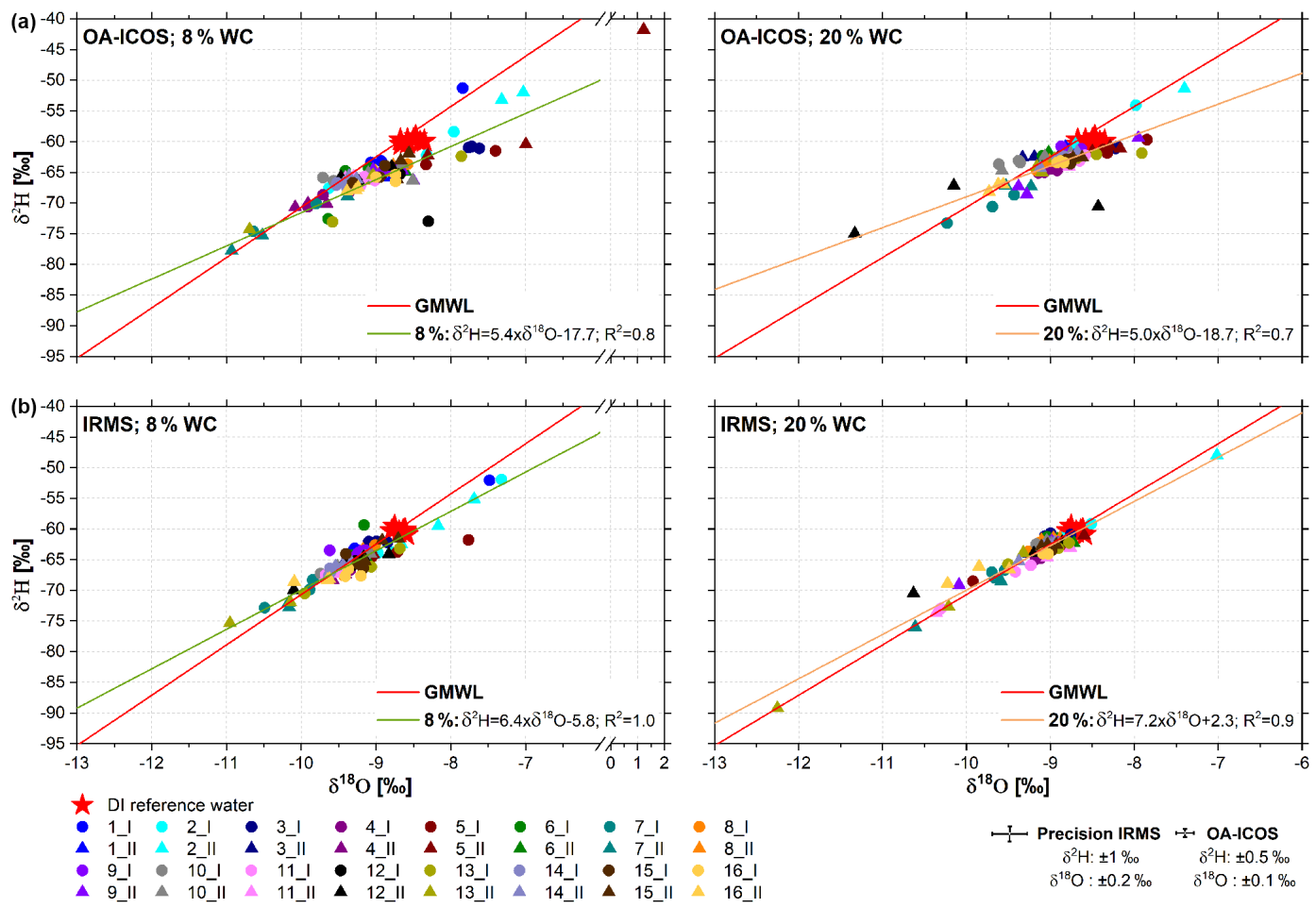

Figure 6. Dual isotope plots of silty sand extracts for 8 and $20 \% \mathrm{WC}$ in comparison to reference DI water (red asterisks) for OA-ICOS and IRMS data (panels a, b, respectively) from the 16 participating labs (different colors represent different labs) and both extraction methods (lab procedure: I; predefined: II). For reference, plots include the global meteoric water line (GMWL, solid red line) and soil water regression lines for 8 and $20 \% \mathrm{WC}$ (solid green and orange lines, respectively).

spheric water vapor to enter the system) or to a remoistening of the oven-dried soil samples before water extraction. Remoistening of oven-dried soil samples might be a general problem of such spiking experiments. In our case, sample preparation was not performed under an inert gas flow and, unfortunately, data on temperature and relative humidity conditions under which sample preparation took place are unavailable from the respective labs. Ambient water vapor isotopic composition measurements would have also been a relevant additional information. Contamination could also occur when an extraction system is not dried or cleaned after each extraction run, leaving moisture and/or soil material behind which would affect the next sample's results. Other measurement uncertainties during the extraction protocol could arise from weighing errors (scale calibration and precision), the accuracy of the volume of water additions to the soil samples, transfer of the samples, loss of water vapor during evacuation of the extraction system, unsteady heating temperatures, condensation of water vapor in the extraction system, and a lack of precision of analytical and laboratory equipment.

It is also possible that participating labs did not follow the predefined extraction procedure (approach II) in the exactly same ways. Even extraction results from some individual labs for the same soil type and WC showed high SDs
(Figs. 3 and 4), which questions the overall repeatability of individual water extraction results. For the first, in-house extraction approach I, not all laboratories indicated the precise extraction conditions (extraction temperature, time, and vacuum) that they used for the specific soil types and WCs.

As an additional performance test, laboratories were asked to perform simple water extractions to show their ability to recover water of known isotopic composition prior to soil-based tests. For example, some laboratories, like lab 2 , showed a high accuracy for these water extractions of $\pm 0.4 \%$ o for $\delta^{2} \mathrm{H}$ and $\pm 0.1 \%$ o for $\delta^{18} \mathrm{O}(n=119)$, as well as lab 16. They performed extraction tests with tap water, which resulted in no significant differences between the initial, untreated $\left(-56.7 \pm 0.4 \%\right.$ of $\delta^{2} \mathrm{H}$ and $-9.3 \pm 0.1 \%$ o for $\left.\delta^{18} \mathrm{O}\right)$ and extracted tap water $\left(-57.5 \pm 0.6 \%\right.$ for $\delta^{2} \mathrm{H}$ and $-9.4 \pm 0.1 \%$ o for $\delta^{18} \mathrm{O}$ ). These examples show that these labs among others were able to reach the TSD with simple water extractions, but with soils they were unsuccessful. This indicates that differences between the reference DI water and water spiked and extracted from soils are likely caused by interactions with soil particles.

Given our findings, we now question the standard quality controls (e.g., water recovery rate calculations and water extractions without soil material). Quality controls with spiked soil samples may be a more effective way to demon- 

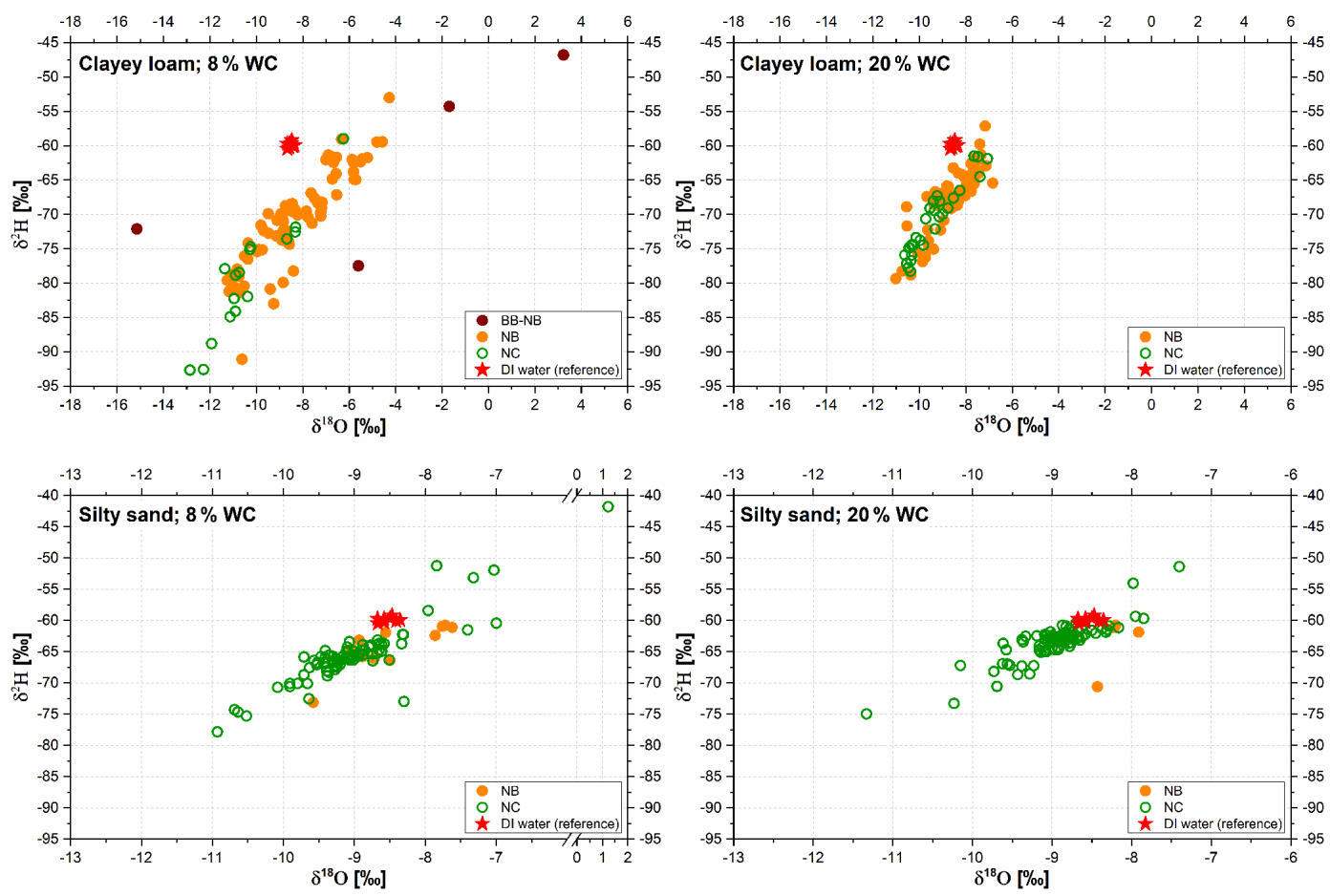

Figure 7. Dual isotope plots of clayey loam and silty sand extracts for 8 and $20 \% \mathrm{WC}$ in comparison to reference DI water (red asterisks) for OA-ICOS analyses flagged by spectral contamination using the Spectral Contamination Identifier (LWIA-SCI) post-processing software (Los Gatos Research Inc.). BB-NB: Broad- and narrowband absorbers (ethanol and methanol); NB: narrowband absorber (methanol); NC: no contamination detected.

strate lab's internal accuracy. However, such spiking experiments as performed in our study come along with other issues as recently outlined by Gaj et al. (2017b) and Sprenger et al. (2015). Gaj et al. (2017a) applied the Rayleigh equation (using stable isotope signatures) to calculate how much water was cryogenically extracted from pure clay minerals. They found that for samples from which water has been extracted to $100 \%$ (determined gravimetrically), the Rayleigh equation showed that only $72 \%$ of water was extracted at a temperature of $105^{\circ} \mathrm{C}$. When using an extraction temperature of $205^{\circ} \mathrm{C}$, the Rayleigh-estimated amount of water extracted was close to $90 \%$, but still not $100 \%$. This result clearly shows that despite the gravimetric quality control suggesting that all water has been extracted, isotopic differences may still exist.

Overall, laboratories 9 (for $\delta^{2} \mathrm{H}$ ) and 13 (for $\delta^{18} \mathrm{O}$ ) were the most successful in getting back to the DI reference water over all soil types and WCs. For the lab's in-house procedure, laboratory 9 extracted both soils for $90 \mathrm{~min}$ at $95^{\circ} \mathrm{C}$ and $0.8 \mathrm{~Pa}$. Their reported water extraction efficiency was 99-100\%. Glass tubes were used as extraction containers and a water bath as heating element. Laboratory 13 used different extraction parameters, which also varied slightly from sample to sample: for the clayey loam at $8 \% \mathrm{WC}$, extractions were conducted for $75-114 \mathrm{~min}$ at $150-100^{\circ} \mathrm{C}$ and 8 13.3 Pa. For the $20 \% \mathrm{WC}$, they used $266 \mathrm{~min}$ at $100^{\circ} \mathrm{C}$ and
6.7-13.3 $\mathrm{Pa}$ as in-house extraction parameters. For the silty sand at $8 \% \mathrm{WC}$, their extraction time was $15 \mathrm{~min}$ at $100^{\circ} \mathrm{C}$ and 7.3-13.3 Pa. For the $20 \% \mathrm{WC}$, they extracted for $30 \mathrm{~min}$ at $100^{\circ} \mathrm{C}$ and $6.7-10.7 \mathrm{~Pa}$. Lab 13 further specified that their extraction times were dictated by a decline in the pressure level indicating that no more water was evaporating from the respective sample. Extraction efficiencies for lab 13 varied between 93 and $127 \%$. Glass tubes were used as extraction containers along with a sensor-regulated tube-shaped heating element. This example shows that even for the relatively successful laboratories, extraction parameters did not seem to play a major role in achieving the reference DI water isotopic signature.

\subsection{How do soil type and water content affect the results?}

The adsorbed and interlayer water occurring in clayey soils can complicate the interpretation of obtained isotope data. Clay water-sorption capacity is well known (Schuttlefield et al., 2007; White and Pichler, 1959). White and Pichler (1959) found early on that montmorillonite adsorbs more water than kaolinite, illite, and chlorite, while chlorites and illites have similar water-sorption properties. The amount of water absorbed/adsorbed by clay minerals ranges from 800 to $500 \%$ for Na montmorillonite (Kaufhold and Dohrmann, 2008; 
White and Pichler, 1959) to as low as $60 \%$ of the initial dry weight for biotite (White and Pichler, 1959). The clayey loam in our study was a vermiculite-rich (43 relative \%) $2: 1$ clay type, while the silty sand had a negligible clay fraction $(2.6 \%)$ where illite $(2: 1$ clay type) occurred with 28 relative \% (Table 2 ).

Since Grim and Bradley (1940), we know that the absorbed/adsorbed water is difficult to remove. Savin and Epstein (1970) as well as Van De Velde and Bowen (2013) have demonstrated that the removal of interlayer and adsorbed water on clay soils can occur when they are heated at 100 to $300^{\circ} \mathrm{C}$ under vacuum conditions. After clay minerals lose all their water, their structure changes. Hence, care should be taken in order to remove clay minerals' water, but keep their structure. Otherwise, rewetting experiments as presented here in our intercomparison might not be valid.

Savin and Epstein (1970) also observed that atmospheric vapor exchanged isotopically with interlayer water (almost completely) and Aggarwal et al. (2004) showed that this can occur within hours. This demonstrated that the isotopic composition of clay interlayer and adsorbed water can reflect the isotopic composition of atmospheric water vapor at the storage location. However, once the soil has been heated under vacuum and the interlayer water removed, the remaining water showed no evidence of isotopic exchange. Again, it should be stressed here that for our intercomparison, soil samples were oven-dried twice (before and after shipment) prior to any rewetting and labs were advised to store the dried samples in a desiccation chamber until use. However, oven-drying was performed at an intermediate temperature $\left(105^{\circ} \mathrm{C}\right.$ for $\left.48 \mathrm{~h}\right)$ and not under vacuum as per Savin and Epstein (1970), and different indoor laboratory "climatic conditions" at the participating laboratories were observed. Thus, it might be possible that not all of the clay interlayer and adsorbed water was removed or made isotopically non-exchangeable, and that non-equilibrium isotopic fractionation occurring at different temperatures during heating might be responsible for some of the differences we observed. Thus, sample preparation might have played its role, when it comes to discrepancies in the labs' results, especially those at low water contents. At these low water contents, the available water fraction is small, and exchange with interlayer and adsorbed water would be proportionally higher. In hindsight, repeating this work with soils dried under vacuum and at higher temperatures (i.e., $300^{\circ} \mathrm{C}$ following Savin and Epstein, 1970) may help to clarify and to isolate the effect of remaining water in clay minerals. However, so far, regular oven-drying of soils is standard practice (Koeniger et al., 2011) for such rewetting experiments in the literature.

We also observed water content effects on the recovered isotope data as per Meißner et al. (2014). Cryogenically extracted isotope data across labs were closer to the added reference water isotopic composition at higher WCs. However, this isotope effect cannot be considered independent from other soil property effects such as clay mineral water interac- tions or effects caused by cation exchange capacity (CEC). Oerter et al. (2014) demonstrated that isotope effects due to soil type are more common in soils with high cation exchange capacity at low WCs. This can be further exacerbated by the cations present in the soil. Those soils with high ionic potential (e.g., $\mathrm{Ca}^{2+}$ and $\mathrm{Mg}^{2+}$ ) can create large amounts of structured water surrounding them (hydrated radii) compared to the bulk water in the system. From an oxygen isotope perspective, O'Neil and Truesdell (1991) showed that those cations are capable of causing fractionation between bound and bulk soil water. Moreover, soils higher in potassium ions may have a greater effect on hydrogen isotopes, while sodium soils demonstrate non-fractionating effects (Oerter et al., 2014). These cation fractionation effects for montmorillic soils, in particular, can result in a depletion of up to $1.55 \%$ in dry soils and $0.49 \%$ for $\delta^{18} \mathrm{O}$ for wet soils. In our study, chemical and salinity effects - which occur due to the fractionation of water molecules into hydration spheres around fully solvated cations compared to the pure water used to make the solutions - can be ignored for the silty sand due to a low CEC of $4.1 \mathrm{cmol}(+) \mathrm{kg}^{-1}$. The high CEC $\left(30.6 \mathrm{cmol}(+) \mathrm{kg}^{-1}\right)$ of the clayey loam soil may have caused some of the detrimental effects seen across laboratories. This is especially the case for low WCs due to ion hydration effects among the cations present (Table 2).

Gaj et al. (2017a) found out that the higher the abundance of $\mathrm{Al}_{2} \mathrm{O}_{3}$ or $\mathrm{Fe}_{2} \mathrm{O}_{3}$, commonly found in clay-rich soils, the lower the ability to isotopically recover added water during spiking experiments. Our clayey loam contained $65 \%$ of $\mathrm{SiO}_{2}$ but still $9 \%$ of $\mathrm{Al}_{2} \mathrm{O}_{3}$, which might have affected the obtained isotope composition in general but cannot be an explanation for the high variability across labs.

\subsection{Differences between OA-ICOS- and IRMS-based measurements}

Our OA-ICOS vs. IRMS comparison showed that isotope data were significantly different between the two isotope measurement methods.

Others have found differences in isotope data obtained from laser-based OA-ICOS and CRDS systems (cavity ringdown spectroscopy) in comparison to IRMS isotope data (Martín-Gómez et al., 2015; Wassenaar et al., 2012). In a recently performed test, 235 international laboratories conducting water isotope analyses by OA-ICOS, CRDS, and IRMS were evaluated. Wassenaar et al. (2018) could show that inaccuracy or imprecise performance stemmed mainly from skill- and knowledge-based errors including calculation mistakes, inappropriate or compromised laboratory calibration standards, poorly performing instrumentation, lack of vigilance to contamination, or inattention to unreasonable isotopic outcomes. For the analysis of $\delta^{18} \mathrm{O}$ and $\delta^{2} \mathrm{H}$ via OA-ICOS, Penna et al. (2012) showed that between-sample memory effects can be an additional problem. Memory effects ranged from 14 and $9 \%$ for $\delta^{18} \mathrm{O}$ and $\delta^{2} \mathrm{H}$ measure- 
ments, respectively, but declined to 0.1 and $0.3 \%$ when the first 10 injections of each sample were discarded.

An additional source of error in our study might be that sample preparation for water extraction was performed separately for OA-ICOS and IRMS analysis, but labs were instructed to follow the exact same procedure. Nevertheless, extractions were performed on independent samples, which might have led to differences in the extracts' isotope composition.

Leen et al. (2012) and West et al. (2010) have observed effects of co-extracted organic compounds leading to sample contamination. This can have a knock-on effect on isotope measurements via OA-ICOS. In our study, we found effects caused by organic contamination producing spectral interferences during OA-ICOS measurements (Fig. 7). This was mainly a problem for the clay soil water extracts, where we found narrow- and broadband absorbers to be responsible for some of the outliers in the data sets. It did not seem to be a major issue for the silty sand soil water extracts. However, some labs applied longer extraction times to the clayey loam samples (see Fig. 2) which might have favored the co-extraction of organics. Martín-Gómez et al. (2015) introduced an online oxidation method for organic compounds for samples measured via isotope ratio infrared spectroscopy. The authors showed that this method was able to effectively remove methanol interference, but was not efficient for high concentrations of ethanol.

During an intercomparison water recovery experiment, Walker et al. (1994) faced difficulties in retrieving the added reference water from dry and wet clays, sand, and gypseous sand. They assumed that decomposition of organic matter or extraction of clay structural water could have caused isotope effects. Recently, Orlowski et al. (2016a) observed that $\delta^{2} \mathrm{H}$ values correlated significantly and became progressively lighter with increasing organic carbon content when using CWE. In environmental organic matter, the different existing exchangeable (i.e., labile) hydrogen fractions $(\mathrm{O}-, \mathrm{N}-$, and S-bonded or aromatic hydrogen) can easily interact with ambient water or water vapor (Ruppenthal et al., 2010) and thus are assumed to be the cause of the isotope effects.

Nevertheless, the less expensive, rapid option of the OAICOS is still a viable alternative for routine isotope analyses if no organic contamination issues are found, six or more injections are performed, and the first two or more are discarded (Penna et al., 2012). If organics are present, proper correction schemes as per Martín-Gómez et al. (2015) need to be applied, especially when OA-ICOS data are used in ecohydrological studies. However, so far, correction procedures only account for contamination caused by methanol or ethanol but plant and soil water extracts can contain a variety of different contaminants. Our work showed that the silty sand soil water extracts were mainly free from organic contamination (Fig. 7). Still, data post-processing is highly recommended to detect issues occurring from co-extracted alcoholic compounds.

\subsection{Take-home messages about cryogenic water extraction}

Our lab intercomparison did not find significant correlations between (i) extraction condition parameters such as temperature, time, and applied vacuum and (ii) the obtained isotope data (Fig. 2). Others have shown that extraction time and temperature have significant effects on the CWE isotope data (Goebel and Lascano, 2012; Koeniger et al., 2011; Orlowski et al., 2013, 2016a; West et al., 2006). Gaj et al. (2017b) showed clear relationships between temperature and the release of water from interlayer cations and organics during CWE, which affected isotope values. They suggested using temperatures between 200 and $300^{\circ} \mathrm{C}$ for clay water extractions. However, higher temperatures could cause a release of water by oxidation of organics and dihydroxylation of hydroxide-containing minerals, and the co-extraction of organics could become more important at harsher extraction conditions leading to spectral interferences when OA-ICOS is used. Orlowski et al. (2018) recently explored the effect of CWE for tracing plant source water. The authors tested the ability to match plant water to its putative soil water source(s) by using different $\mathrm{CWE}$ conditions $\left(30-240 \mathrm{~min}, 80-200^{\circ} \mathrm{C}\right.$, $0.1 \mathrm{~Pa}$ ) for a clayey loam (same as in this study) and a pure sand type. They showed that with higher extraction temperatures and longer extraction times, gradually more enriched soil water was extracted, which surprisingly reflected the plants' source water.

Our interlaboratory comparison was not able to provide any recommendations with regard to higher temperatures or longer extraction times leading to possibly better extraction results. Little is known about how the applied extraction pressure affects the CWE isotope data. But one thing is clear: that CWE is a "brute force technique" (Orlowski et al., 2016a) in the sense that it is not able to distinguish between waters held at different soil tensions being of different importance for the ecohydrological water cycle. New instrumentation to sample discretely along the moisture release curve is desperately needed (McDonnell, 2014). For most past studies, possible fractionation effects associated with CWE remain unknown and the applied extraction parameters or cryogenic system specifications are often not indicated. Orlowski et al. (2018) recently stated that observed isotopic fractionation effects potentially lead to errors when CWE isotope data are used for plant water source calculation. This miscalculation in plants' water source could be quite large and could lead to misinterpretations of the role different plant species play in hydrologic processes at the ecosystem or larger scales. Millar et al. (2018) used the most common water extraction methods (centrifugation, microwave extraction, direct vapor equilibration, high-pressure mechanical squeezing, and two different CWE systems) for their intercomparison study on spring wheat (Triticum aestivum L.). The authors showed that all methods yielded markedly different isotopic signatures. The various methods also produced differing concentrations 
of co-extracted organic compounds. Again, CWE was outperformed by other extraction methods.

We found significant differences between extraction approach I (lab in-house procedure) and II (predefined extraction parameters). Both approaches showed significant differences compared to the added reference water for the OAICOS results, but in different ways. For example, for $\delta^{2} \mathrm{H}$ signature recovery from silty sand, extraction approach II worked better. The same was true for $\delta^{18} \mathrm{O}$ signature recovery for both WC treatments. However, for other settings, it was difficult to identify the ideal extraction approach that got closer to the reference DI water isotopic composition. We found no clear tendency for which approach should be applied, thus at present, and much to our dismay, we cannot define any standard protocol for CWE. In the light of our experience with other soil water extraction techniques (Orlowski et al., 2016b), we argue that the success of any of these methods may depend more on the specific understanding and operation leading to internal reproducibility of each individual technique's results than an inherent superiority of one technique over another.

We could show with our interlaboratory comparison that a number of factors affect CWE results among which soil properties such as clay mineral composition and concomitant release of interlayer water seemed to be important. It is therefore essential to obtain detailed soil property information to be able to apply post-corrections as per Gaj et al. (2017a). Further research is urgently needed to analyze the full extent of soil organic matter effects (i.e., exchangeable bonded hydrogen; Meißner et al., 2014) in organic-rich soils on the cryogenically extracted isotopic composition.

Future studies should test clay mineral fractionation effects on $\delta^{18} \mathrm{O}$ and $\delta^{2} \mathrm{H}$ during CWEs individually. We further recommend running individual CWE spiking tests on each natural soil material originating from field studies, also considering spatial variability of soil physicochemical properties over depth. Comparing the isotopic deviation of results from such spiking experiments with results from standardized soils will help to establish system-specific transfer functions. This will require considerable effort. However, it seems to be the only way to have some sort of calibration function for each extraction system and different soil types with their clay mineral composition.

\section{Conclusions}

This work presents results from a worldwide round robin laboratory intercomparison test of cryogenic extraction systems for soil water isotopic analysis. We tested the null hypothesis that, with identical soils, standards, and isotope analyses, cryogenic extraction across laboratories should yield identical isotopic composition. The 16 participating laboratories used the same two standard soils along with reference water of known isotopic composition for CWEs. With our in- terlaboratory comparison, we showed that multiple factors influence extracted isotopic signatures. Soil type, water content, and the applied type of isotope analysis (OA-ICOS vs. IRMS) showed major impacts, whereas applied extraction parameters (time, temperature, and vacuum) interestingly did not affect CWE isotope data across laboratories. Laboratory internal quality and water recovery rates showed additional effects.

Although the applied extraction system setups were different (e.g., size of extraction container, heating unit), we could not show a major impact of the system's design on the obtained isotope data, as laboratories were successful for the one soil type and water content but failed for the other. However, internal reproducibility for the replicates of the same soil type at a given WC was given for most of the labs. Nevertheless, different results were obtained for $\delta^{18} \mathrm{O}$ and $\delta^{2} \mathrm{H}$.

Our intercomparison work showed that defining any sort of standard extraction procedure for CWEs across laboratories is challenging. Our results question the usefulness of this method as a standard for water extraction since results are not intercomparable across laboratories. A possible option might be that CWE labs establish system-specific calibration functions for each natural soil type, individually, to correct for the given offset to a set of reference soils.

New method intercomparison work on plant material showed that direct vapor equilibration is probably the most suitable extraction technique to be used when investigating plant water sourcing, at least for wheat. However, an inter-laboratory comparison is still lacking and should be addressed for plants in the future to account for possible effects. New continuous, in situ measurements of soil and plant water isotopic composition might overcome isotope fractionation issues we observed with CWE.

Data availability. The data are available upon request. 
Appendix A: Cryogenic water extraction (CWE) system

- Questionnaire

\section{Inter-laboratory comparison of CWE systems}

\begin{tabular}{l|l|l} 
& \multicolumn{2}{|c}{ First Name } \\
\cline { 2 - 3 } Contact person & Last Name & \\
\cline { 2 - 3 } Address & \multicolumn{2}{|c}{ Street No. } \\
\hline Street & Postal Code Country \\
\hline City & \\
\hline Phone Number & \multicolumn{2}{|c|}{ Email }
\end{tabular}

\section{Cryogenic system - Questionnaire}

How many numbers of extraction slots/units does your cryogenic extraction system have?

How much sample material (in gramm) is required for the cryogenic extraction at your system?

Does your laboratory have an operating procedure in terms of temperature, vacuum settings, and extraction times for soil and plant samples?

Do you have the possibility to adjust the extraction conditions (temperature, vacuum)?

To which type of sample material do you apply the cryogenic extraction method?

\begin{tabular}{l|l} 
& \\
\hline Type of plant material (e.g., twig, root crown) $\quad$ Soil type
\end{tabular}

Please provide us a photo of your cryo-line. 
Author contributions. NO, LB, and JJ McD designed the experiment. All co-authors conducted the laboratory work. NO analyzed the data statistically with the support of Nathalie Steiner. All authors were involved in the data interpretation. NO prepared the manuscript and all co-authors were asked to review the manuscript.

Competing interests. The authors declare that they have no conflict of interest.

Acknowledgements. This interlaboratory test would not have been possible without the generous cooperation of the researchers and technical staff in our 16 stable water isotope laboratories. We especially thank Kim Janzen, Cody Millar, and Anna Winkler for their laboratory support and Nathalie Steiner for statistical support. The Gibson laboratory from Alberta Innovates Technology Futures is thanked for IRMS analyses. This research was supported by an NSERC Discovery Grant and Accelerator Award to Jeffrey J. McDonnell.

Edited by: Thom Bogaard

Reviewed by: Daniele Penna, Niels Munksgaard, and one anonymous referee

\section{References}

Aggarwal, P. K., Dillon, M. A., and Tanweer, A.: Isotope fractionation at the soil-atmosphere interface and the ${ }^{18} \mathrm{O}$ budget of atmospheric oxygen, Geophys. Res. Lett., 31, 1-4, https://doi.org/10.1029/2004GL019945, 2004.

Araguás-Araguás, L., Rozanski, K., Gonfiantini, R., and Louvat, D.: Isotope effects accompanying vacuum extraction of soil water for stable isotope analyses, J. Hydrol., 168, 159-171, https://doi.org/10.1016/0022-1694(94)02636-P, 1995.

Benettin, P., Volkmann, T. H. M., von Freyberg, J., Frentress, J., Penna, D., Dawson, T. E., and Kirchner, J. W.: Effects of climatic seasonality on the isotopic composition of evaporating soil waters, Hydrol. Earth Syst. Sci., 22, 2881-2890, https://doi.org/10.5194/hess-22-2881-2018, 2018.

Brand, W. A., Geilmann, H., Crosson, E. R., and Rella, C. W.: Cavity ring-down spectroscopy versus high-temperature conversion isotope ratio mass spectrometry; a case study on $\delta^{2} \mathrm{H}$ and $\delta^{18} \mathrm{O}$ of pure water samples and alcohol/water mixtures, Rapid Commun. Mass Sp., 23, 1879-1884, https://doi.org/10.1002/rcm.4083, 2009.

Craig, H.: Standard for Reporting Concentrations of Deuterium and Oxygen-18 in Natural Waters, Science, 133, 1833-1834, https://doi.org/10.1126/science.133.3467.1833, 1961.

Gaj, M., Kaufhold, S., Koeniger, P., Beyer, M., Weiler, M., and Himmelsbach, T.: Mineral mediated isotope fractionation of soil water, Rapid Commun. Mass Sp., 31, 269-280, https://doi.org/10.1002/rcm.7787, 2017a.

Gaj, M., Kaufhold, S., and McDonnell, J. J.: Potential limitation of cryogenic vacuum extractions and spiked experiments, Rapid Commun. Mass Sp., https://doi.org/10.1002/rcm.7850, 2017b.

Goebel, T. S. and Lascano, R. J.: System for high throughput water extraction from soil material for stable isotope anal- ysis of water, J. Anal. Sci. Methods Instrum., 2, 203-207, https://doi.org/10.4236/jasmi.2012.24031, 2012.

Gonfiantini, R.: Environmental isotopes in lake studies, in: Handbook of environmental isotope geochemistry: The terrestrial environment, B, edited by: Fritz, P. and Fontes, J. C., 113-168, Elsevier, New York, USA, 1986.

Grim, R. and Bradley, W.: Investigation of the Effect of Heat on the Clay Minerals Illite and Montmorillonite, J. Am. Ceram. Soc., 23, 242-248, https://doi.org/10.1111/j.11512916.1940.tb14263.x, 1940.

IAEA (International Atomic Energy Agency): IAEA/GNIP precipitation sampling guide, available at: http://www-naweb.iaea.org/ napc/ih/documents/other/gnip_manual_v2.02_en_hq.pdf (last access: 15 June 2014), 2014.

Ingraham, N. L. and Shadel, C.: A comparison of the toluene distillation and vacuum/heat methods for extracting soil water for stable isotopic analysis, J. Hydrol., 140, 371-387, https://doi.org/10.1016/0022-1694(92)90249-U, 1992.

Kaufhold, S. and Dohrmann, R.: Comparison of the traditional Enslin-Neff method and the modified dieng method for measuring water-uptake capacity, Clay. Clay Miner., 56, 68600692, https://doi.org/10.1346/CCMN.2008.0560609, 2008.

Koeniger, P., Marshall, J. D., Link, T., and Mulch, A.: An inexpensive, fast, and reliable method for vacuum extraction of soil and plant water for stable isotope analyses by mass spectrometry, Rapid Commun. Mass Sp., 25, 3041-3048, https://doi.org/10.1002/rcm.5198, 2011.

Leen, J. B., Berman, E. S. F., Liebson, L., and Gupta, M.: Spectral contaminant identifier for off-axis integrated cavity output spectroscopy measurements of liquid water isotopes, Rev. Sci. Instrum., 83, 044305, https://doi.org/10.1063/1.4704843, 2012.

LUFA Speyer: German State Research Institute for Agriculture, Speyer, DE, available at: http://www.lufa-speyer.de/index.php/ dienstleistungen/standardboeden/8-dienstleistungen/artikel/ 57-standard-soils (last access: 15 April 2015), 2015.

Martín-Gómez, P., Barbeta, A., Voltas, J., Peñuelas, J., Dennis, K., Palacio, S., Dawson, T. E., and Ferrio, J. P.: Isotoperatio infrared spectroscopy: a reliable tool for the investigation of plant-water sources?, New Phytol., 207, 914-927, https://doi.org/10.1111/nph.13376, 2015.

McDonnell, J. J.: The two water worlds hypothesis: ecohydrological separation of water between streams and trees?, Wiley Interdiscip. Rev. Water, 1, 323-329, https://doi.org/10.1002/wat2.1027, 2014.

Meißner, M., Köhler, M., Schwendenmann, L., Hölscher, D., and Dyckmans, J.: Soil water uptake by trees using water stable isotopes $\left(\delta^{2} \mathrm{H}\right.$ and $\left.\delta^{18} \mathrm{O}\right)-$ a method test regarding soil moisture, texture and carbonate, Plant Soil, 376, 327-335, https://doi.org/10.1007/s11104-013-1970-z, 2014.

Millar, C., Pratt, D., Schneider, D. J., and McDonnell, J. J.: A comparison of extraction systems for plant water stable isotope analysis, Rapid Commun. Mass Sp., 32, 1031-1044, https://doi.org/10.1002/rcm.8136, 2018.

Morrison, J., Brockwell, T., Merren, T., Fourel, F., and Phillips, A. M.: On-line high-precision stable hydrogen isotopic analyses on nanoliter water samples, Anal. Chem., 73, 3570-3575, 2001.

Nelson, S. T.: A simple, practical methodology for routine VSMOW/SLAP normalization of water samples analyzed by continuous flow methods, Rapid Commun. 
Mass Sp., 14, 1044-1046, https://doi.org/10.1002/10970231(20000630)14:12<1044::AID-RCM987>3.0.CO;2-3, 2000.

Oerter, E., Finstad, K., Schaefer, J., Goldsmith, G. R., Dawson, T., and Amundson, R.: Oxygen isotope fractionation effects in soil water via interaction with cations $(\mathrm{Mg}, \mathrm{Ca}, \mathrm{K}, \mathrm{Na})$ adsorbed to phyllosilicate clay minerals, J. Hydrol., 515, 1-9, https://doi.org/10.1016/j.jhydrol.2014.04.029, 2014.

O'Neil, J. R. and Truesdell, A. H.: Oxygen isotope fractionation studies of solute-water interactions, in: Stable Isotope Geochemistry: A Tribute to Samuel Epstein, Vol. 3, edited by: Taylor Jr., H., O’Neil, J. R., and Kaplan, I. R., 17-25, Geochem. Soc, Washington, D.C., USA, 1991.

Orlowski, N., Frede, H.-G., Brüggemann, N., and Breuer, L.: Validation and application of a cryogenic vacuum extraction system for soil and plant water extraction for isotope analysis, J. Sens. Sens. Syst., 2, 179-193, https://doi.org/10.5194/jsss-2-179-2013, 2013.

Orlowski, N., Breuer, L., and McDonnell, J. J.: Critical issues with cryogenic extraction of soil water for stable isotope analysis, Ecohydrol., 9, 1-5, https://doi.org/10.1002/eco.1722, 2016a.

Orlowski, N., Pratt, D. L., and McDonnell, J. J.: Intercomparison of soil pore water extraction methods for stable isotope analysis, Hydrol. Process., 30, 3434-3449, https://doi.org/10.1002/hyp.10870, 2016 b.

Orlowski, N., Winkler, A., McDonnell, J. J., and Breuer, L.: A simple greenhouse experiment to explore the effect of cryogenic water extraction for tracing plant source water, Ecohydrology, e1967, https://doi.org/10.1002/eco.1967, 2018.

Penna, D., Stenni, B., Šanda, M., Wrede, S., Bogaard, T. A., Michelini, M., Fischer, B. M. C., Gobbi, A., Mantese, N., Zuecco, G., Borga, M., Bonazza, M., Sobotková, M., Cejková, B., and Wassenaar, L. I.: Technical Note: Evaluation of between-sample memory effects in the analysis of $\delta^{2} \mathrm{H}$ and $\delta^{18} \mathrm{O}$ of water samples measured by laser spectroscopes, Hydrol. Earth Syst. Sci., 16, 3925-3933, https://doi.org/10.5194/hess-16-3925-2012, 2012.

Poppe, L. J., Paskevich, V. F., Hathaway, J. C., and Blackwood, D. S.: USGS, U.S. Geological Survey, Coastal and Marine Geology Program, Open-File Report 01-041: A Laboratory Manual for X-Ray Powder Diffraction, available at: http://pubs.usgs. gov/of/2001/of01-041/htmldocs/intro.htm (last access: 12 October 2016), 2016.

R Core Team: R: A language and environment for statistical computing, R Foundation for Statistical Computing, Vienna, Austria, 2014.

Rozanski, K., Araguás-Araguás, L., and Gonfiantini, R.: Isotopic Patterns in Modern Global Precipitation, in: Climate Change in Continental Isotopic Records, edited by: Swart, P. K., Lohmann, K. C., Mckenzie, J., and Savin, S., 1-36, American Geophysical Union, Washington, D.C., USA, 1993.

Ruppenthal, M., Oelmann, Y., and Wilcke, W.: Isotope ratios of nonexchangeable hydrogen in soils from different climate zones, Geoderma, 155, 3-4, https://doi.org/10.1016/j.geoderma.2009.12.005, 2015.

Savin, S. M. and Epstein, S.: The oxygen and hydrogen isotope geochemistry of clay minerals, Geochim. Cosmochim. Ac., 34, 2542, https://doi.org/10.1016/0016-7037(70)90149-3, 1970.
Schultz, N. M., Griffis, T. J., Lee, X., and Baker, J. M.: Identification and correction of spectral contamination in ${ }^{2} \mathrm{H} /{ }^{1} \mathrm{H}$ and ${ }^{18} \mathrm{O} /{ }^{16} \mathrm{O}$ measured in leaf, stem, and soil water, Rapid Commun. Mass Sp., 25, 3360-3368, https://doi.org/10.1002/rcm.5236, 2011.

Schuttlefield, J., Cox, D., and Grassian, V.: An investigation of water uptake on clays minerals using ATRFTIR spectroscopy coupled with quartz crystal microbalance measurements, J. Geophys. Res.-Atmos., 112, 1-14, https://doi.org/10.1029/2007JD008973, 2007.

Sprenger, M., Herbstritt, B., and Weiler, M.: Established methods and new opportunities for pore water stable isotope analysis, Hydrol. Process., 29, 5174-5192, https://doi.org/10.1002/hyp.10643, 2015.

Van De Velde, J. H. and Bowen, G. J.: Effects of chemical pretreatments on the hydrogen isotope composition of $2: 1$ clay minerals, Rapid Commun. Mass Sp., 27, 1143-1148, https://doi.org/10.1002/rcm.6554, 2013.

Walker, G. R., Woods, P. H., and Allison, G. B.: Interlaboratory comparison of methods to determine the stable isotope composition of soil water, Chem. Geol., 111, 297-306, https://doi.org/10.1016/0009-2541(94)90096-5, 1994.

Wassenaar, L., Ahmad, M., Aggarwal, P., van Duren, M., Pöltenstein, L., Araguas, L., and Kurttas, T.: Worldwide proficiency test for routine analysis of $\delta^{2} \mathrm{H}$ and $\delta^{18} \mathrm{O}$ in water by isotope-ratio mass spectrometry and laser absorption spectroscopy, Rapid Commun. Mass Sp., 26, 1641-1648, https://doi.org/10.1002/rcm.6270, 2012.

Wassenaar, L. I., Terzer-Wassmuth, S., Douence, C., AraguasAraguas, L., Aggarwal, P. K., and Coplen, T. B.: Seeking excellence: An evaluation of 235 international laboratories conducting water isotope analyses by isotope-ratio and laserabsorption spectrometry, Rapid Commun. Mass Sp., 32, 393406, https://doi.org/10.1002/rcm.8052, 2018.

West, A. G., Patrickson, S. J., and Ehleringer, J. R.: Water extraction times for plant and soil materials used in stable isotope analysis, Rapid Commun. Mass Sp., 20, 1317-1321, https://doi.org/10.1002/rcm.2456, 2006.

West, A. G., Goldsmith, G. R., Brooks, P. D., and Dawson, T. E.: Discrepancies between isotope ratio infrared spectroscopy and isotope ratio mass spectrometry for the stable isotope analysis of plant and soil waters, Rapid Commun. Mass Sp., 24, 1948-1954, https://doi.org/10.1002/rcm.4597, 2010.

White, W. A. and Pichler, E.: Water Sorption Properties of Clay Minerals (No. 208), available at: https: //www.ideals.illinois.edu/bitstream/handle/2142/44988/ watersorptioncha266whit.pdf?sequence $=2$ (last access: 10 October 2015), 1959.

Zieffler, A. S., Harring, J. R., and Long, J. D.: 12. Unplanned Contrasts, in Comparing Groups: Randomization and Bootstrap Methods Using R, 255-286, John Wiley \& Sons, New York, NY, USA, 2012. 